\title{
An Operation Strategy of the Hybrid Multi-Terminal HVDC for Contingency
}

\author{
Sungchul Hwang ${ }^{1} \mathbb{D}$, Sungyoon Song ${ }^{1}{ }^{\mathbb{D}}$, Gilsoo Jang ${ }^{1} \mathbb{D}$ and Minhan Yoon ${ }^{2, *}$ \\ 1 School of Electrical Engineering, Korea University, 145 Anam-ro, Seongbuk-gu, Seoul 02841, Korea; \\ adidas@korea.ac.kr (S.H.); blue6947@korea.ac.kr (S.S.); gjang@korea.ac.kr (G.J.) \\ 2 Department of Electrical Engineering, Tongmyong University, 428 Sinseon-ro, Nam-gu, Busan 48520, Korea \\ * Correspondence: mhyoon@tu.ac.kr; Tel.: +82-51-629-1313
}

Received: 24 April 2019; Accepted: 24 May 2019; Published: 28 May 2019

\begin{abstract}
The application of the direct current (DC) transmission is increasing through the interconnection between grids or the renewable energy resource integration. Various types of DC transmission topology are researched, and the hybrid multi-terminal high voltage DC (HVDC), called the "MTDC", is one of the research subjects. The hybrid multi-terminal HVDC is the MTDC system that is composed with the Line Commutated Converter (LCC) and Voltage Source Converter (VSC). Most hybrid MTDC research has been focused on the connection of the renewable energy generation sources, especially offshore wind farms. However, the DC grid built with a hybrid MTDC was recently proposed due to the development of the converter technology. Therefore, the DC grid is expected to be able to substitute some parts of the transmission grid instead of the alternating current (AC) system, and the operation strategies of the DC grid are still being researched. The DC grid has the advantage of being able to control the power flow, which can even improve the stability of the connected AC system. The dynamic model is required to analyze the improvement of the AC system by the operation strategy of the hybrid MTDC, however, there is no generic model for the system. In this paper, an operation strategy of the hybrid MTDC is proposed to improve the stability of the AC power system by increasing the utilization of parallel AC transmission lines under the contingency condition. Furthermore, studies on the modeling method for a hybrid MTDC analysis were performed. The proposed modeling method and operation strategy were verified in simulations for which a modified IEEE 39 bus test system was used. The improvement of transient stability by the proposed hybrid MTDC system was shown in the simulation results.
\end{abstract}

Keywords: HVDC transmission; hybrid multi-terminal HVDC; LCC; MTDC; power system analysis; VSC

\section{Introduction}

The power system has been growing steadily according to the development of alternating current (AC) technology. However, the development of the AC system has been recently saturated, and the construction of a new AC transmission line is becoming more difficult, due to problems such as environmental issues or protests from local residents regarding the right of way. The new construction of a transmission line or the utilization of the existing AC lines is required to supply power stably for increasing loads. The flexible AC transmission system (FACTS) is now regarded as a promising option, due to the capability to utilize the existing AC system by controlling the power flow or the voltage compensation [1-3]. It is expected that the development of power electronics technology promotes the FACTS device extensively [4]. The direct current (DC) transmission system is especially on the rise around the world and consistently examined in terms of an alternative to the AC transmission line. Furthermore, research on the DC grid is actively performed to provide a power control capability. 
Studies on the feasibility of the DC grid with various topologies, grid controls, and protection schemes are being conducted [5]. In addition, much research is performed on grid management and the voltage droop control strategy [6-8].

The control and operation technology of the multi-terminal high voltage DC (HVDC), known as the "MTDC", is fundamental for building and operating the DC grid. The MTDC is used for the HVDC systems consisting of three or more converters and can control the power flow between the converter stations. At the beginning of the MTDC study, the system configuration and normal operation point is introduced in [9] and operation characteristic of MTDC is studied in [10]. Although the Line Commutate Converter (LCC) type was mainly studied in the early research, Voltage Source Converter (VSC)-type MTDC has been mainly researched recently, due to the development of VSC technology. Various research studies on the VSC MTDC, such as the AC and DC system power flow calculations with the VSC MTDC [11,12], the transmission loss minimization [13], and the frequency control [14], have been performed. The recent subjects of research on the hybrid MTDC are mainly control for the system, such as droop control, fault ride through, and voltage-dependent current order limiter [15-17]. Regarding the system stability, small signal stability is studied in [18].

Notably, numerous MTDC studies have dealt with the integration of offshore wind farms [19-21], because the MTDC system possesses the advantages for the integration of remote renewable resources. Since fine wind resources are abundant on the sea offshore and as offshore wind farms are generally far from main land, the length of the AC cables presents an issue. The MTDC is therefore an attractive option for the collection and integration of several wind farms. The hybrid MTDC systems have also been proposed, due to the advantage of the VSC with weak AC systems. The advantages of the VSC include independent control of active power and reactive power, $\mathrm{AC}$ voltage compensation, and a compact size for installation [22]. The power system of remote renewable resources can be seen as weak systems, and the structure of an offshore wind farm is particularly small for the installation of large scale equipment. Therefore, the VSC can be a proper type of converter to interconnect the resources. Alternatively, the capacity of the LCC is more highly rated compared with the VSC, plus the LCC is cheaper than the VSC in terms of the installation and the operating cost. For this reason, the LCC HVDC has been used for bulk power transmission. Therefore, the hybrid MTDC could be attractive in terms of the advantages of both the LCC and the VSC.

The hybrid HVDC system topologies were introduced in [23] and the technical feasibility of the hybrid MTDC has been studied [24,25]. The integration of the wind farm using the MTDC system and the control strategy were studied in [26-28]. Recently, as the need for DC grid application has increased, the DC grid is expected to coexist with the AC grid; consequently, a study on the control and operation strategy of the MTDC is necessary to establish the DC grid foundation.

In this paper, the proposed operation strategy of the hybrid MTDC seeks to increase the utilization of the AC transmission line in parallel with the MTDC for the power transmission between two regions, in consideration of the contingency condition. To construct the MTDC systems, it is possible to construct a new system in addition to the extension of the existing HVDC system [10,29]. Numerous existing HVDC systems were installed for a bulk power transmission from the generation area to the load area. In the case that the existing LCC HVDC in the AC system is extended to the hybrid MTDC, the constructed DC grid provides flexibility to the AC system through the power flow control. Additionally, it is difficult for the LCC to change the direction of the power flow because power flow reversing with the LCC is discontinuous and has line discharging problems [30]. But the VSC can change the power flow direction more flexibly than the LCC. Therefore, the hybrid MTDC could be relatively more flexible than the LCC MTDC. In the case of the third terminal installation at the parallel AC transmission lines, which is achieved by the extension of the existing LCC HVDC, the utilization of the lines is expected to increase. The method for the increase of the utilization of the AC transmission lines in parallel with the HVDC system through the extension of the HVDC system to the hybrid MTDC system was studied in this paper. The proposed operation strategy was evaluated using a simulation analysis. The hybrid MTDC system was modeled and applied in the modified IEEE 
39 bus New England test system (NETS) [31,32]. The utilization was estimated by considering the contingencies of the AC lines, and the simulation analysis was performed using the Transient Stability Analysis (TSA) tool, PSS ${ }^{\circledR} \mathrm{E}$. The simulation tool is commonly used for large power system analysis and transient stability simulation. The tool has a generic dynamic model for various power devices, except the hybrid MTDC model. The proposed operation strategy was applied in the actual power system data, which is Korean power system data, and the stability improvement of the system by the hybrid MTDC was evaluated.

The structure of the paper is as follows: Section 2 presents the operation strategy for the hybrid MTDC and the modeling method is described and verified in Section 3. The case studies conducted in the test system are introduced in Section 4 . Section 5 presents the results of a case study applying the proposed operation strategy to the actual Korean power system data. Discussion is in Section 6.

\section{Proposed Operation Strategy for the Hybrid MTDC}

The existing LCC HVDC systems in the AC grid supply bulk power from the generation area to the load area. The power can be flowed through certain AC transmission lines according to the magnitude and phase angle of the voltage between two areas. The corridor AC lines can be seen as the lines that are parallel with the HVDC. The HVDC can be extended by installing the third terminal at the bus of the parallel line, thereby establishing the DC grid in the AC grid. The DC grid can provide flexibility to the AC grid via the power flow control. Figure 1 illustrates the power system for which the extended MTDC is applicable.

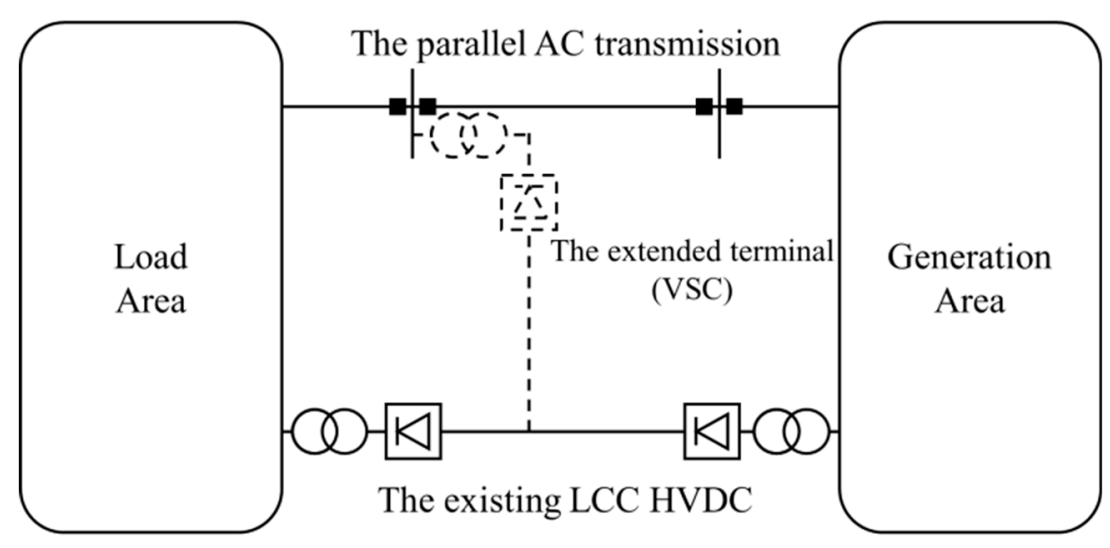

Figure 1. Extended multi-terminal high voltage direct current (MTDC) application in the power system between the generation and load areas.

In this paper, a hybrid MTDC operation strategy that increases the utilization of the parallel AC lines is proposed in consideration of the transient stability. Figure 2 presents the operation strategy briefly in terms of the transient state and the post-contingency condition. When the maintenance or fault occurs on the parallel AC lines, the utilization of remaining lines decreases. The extended terminal can be operated as an inverter or a rectifier to utilize the remaining lines by the operation strategy. The VSC terminal operates as an inverter when an event occurs at the generation side and as a rectifier when an event occurs at the load side. 


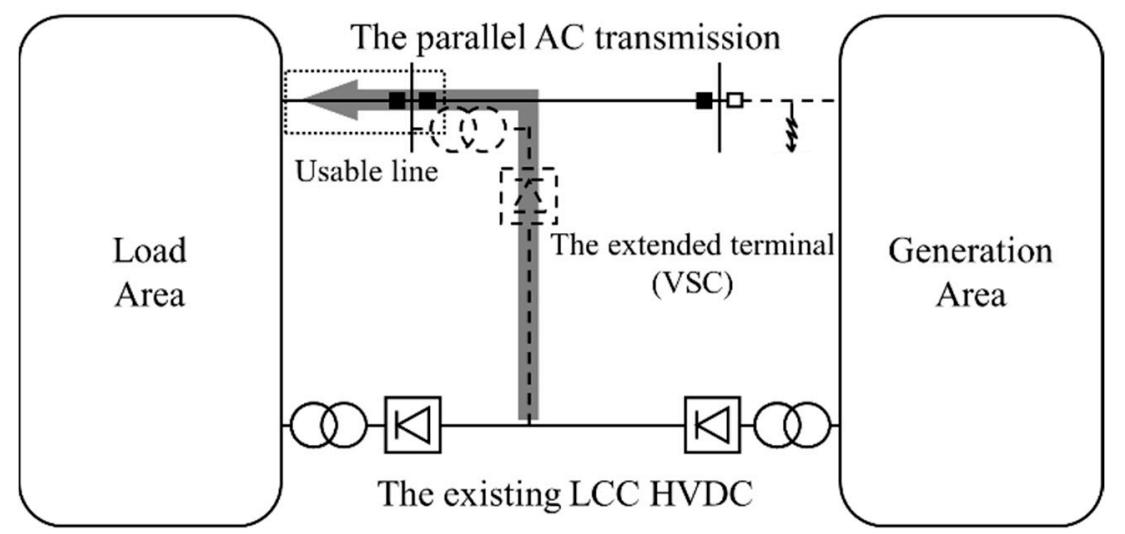

(a)

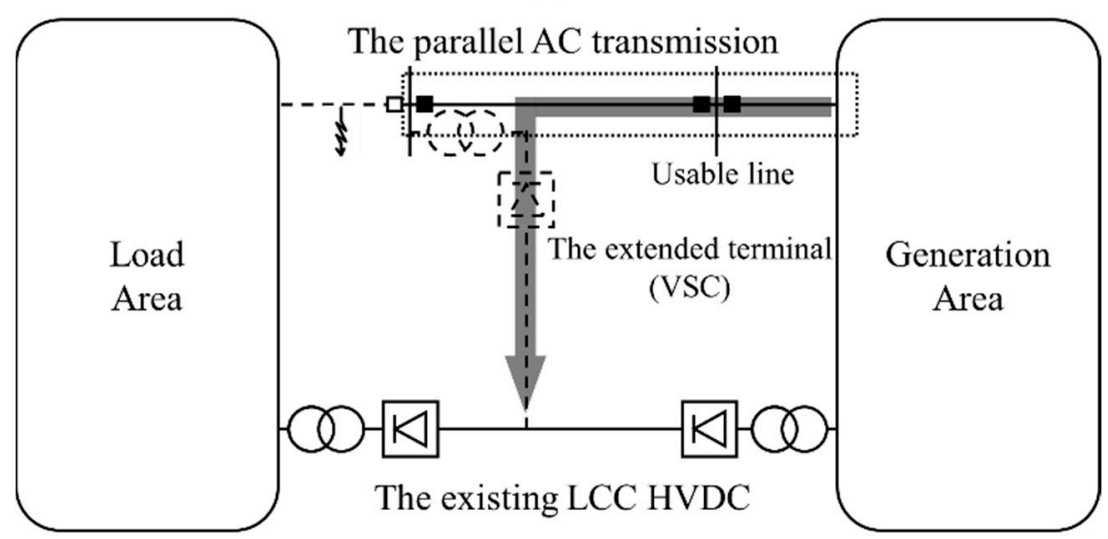

(b)

Figure 2. Brief operation strategy for the extended MTDC: (a) Power flow direction of the Voltage Source Converter (VSC) with the event at the generation side. (b) Power flow direction of the VSC with the event at the load side.

Because the VSC can reverse the power flow direction dynamically, the VSC can provide power to the $\mathrm{AC}$ line at the load area side for the generation side AC line event. In contrast, the generation side AC line can be used via the VSC when the event occurs at the load area AC line. Therefore, the hybrid MTDC is proposed in this paper instead of the LCC MTDC, owing to the consideration of the transient stability.

The need of the existing LCC HVDC system to change the general power flow direction is minor because the purpose of the system is the supply of power from the generation area to the load area. Consequently, the transient stability is expected to improve even with a hybrid MTDC system where the VSC is applied only to the third terminal.

Furthermore, the overload of the DC system was considered in the operation strategy. In the transient status, the unbalanced condition between the generation and load areas causes instability, and even several overload seconds can improve the transient stability; therefore, the proposed operation strategy considered the overload control during the transient status and verified the stability improvement.

\section{Modeling and Analysis Method of the Hybrid MTDC}

Even though the hybrid HVDC system has been researched since 1994, a practical operation has not yet been implemented. In addition, a model of the hybrid HVDC system for a power system analysis with the TSA tool is nonexistent. In light of this circumstance, the users developed the special model for the analysis of the hybrid MTDC via the TSA. In this paper, the method for the hybrid MTDC approximate modeling was studied using a generic multi-terminal model and a Controllable Reactive 
Power Source (CRPS). The LCC multi-terminal HVDC model is a generic MTDC model of PSS ${ }^{\circledR}$ E. The hybrid MTDC model is built by connecting the controllers of the generic model with a programming language Python and making the LCC terminal and CRPS operate as one device. For the analysis of the hybrid MTDC, the third terminal convertor should be a VSC. The important features of the VSC in terms of the AC system are the AC bus voltage control and the independent control of the active and reactive powers. The active power can be controlled by the LCC MTDC model, but the LCC generally consumes the reactive power; therefore, the CRPS model was used to provide the control ability and to compensate for the reactive power. A generic model of Static Compensation (STATCOM) from the PSS ${ }^{\circledR} \mathrm{E}$ is also used for CRPS. The models are explained in the manual of the program [33].

\subsection{Steady State Model of the Hybrid MTDC}

A steady state model is needed for the power flow calculation and the dynamic simulation initialization. To calculate the power flow, the MTDC system is modeled using the generic MTDC model. The angle of the converters, DC voltage, DC current by the order and the active power, and reactive power is calculated in the power flow analysis stage.

The proposed hybrid MTDC has the VSC at the third terminal, and the extended terminal should have the VSC features. A CRPS can control the reactive power and the AC bus voltage, so the CRPS model is composed of the same bus of the LCC MTDC third terminal, as shown in Figure 3. The existing LCC can control the active power, but it consumes the reactive power. The CRPS compensates for the reactive power and provides the control ability as well; therefore, the active and reactive powers can be controlled independently from the viewpoint of the AC bus. The AC bus voltage can also be controlled by the reactive power from the CRPS. The power orders are defined by the main controller to match the requirement of the power system balance and the main controller is implemented using the python programming language. According to the power order produced by the main controller, active power is controlled by the MTDC controller and reactive power is controlled by the CRPS controller. Consequently, the performance of the devices is equivalent to the single VSC performance at the point of the connected AC bus.

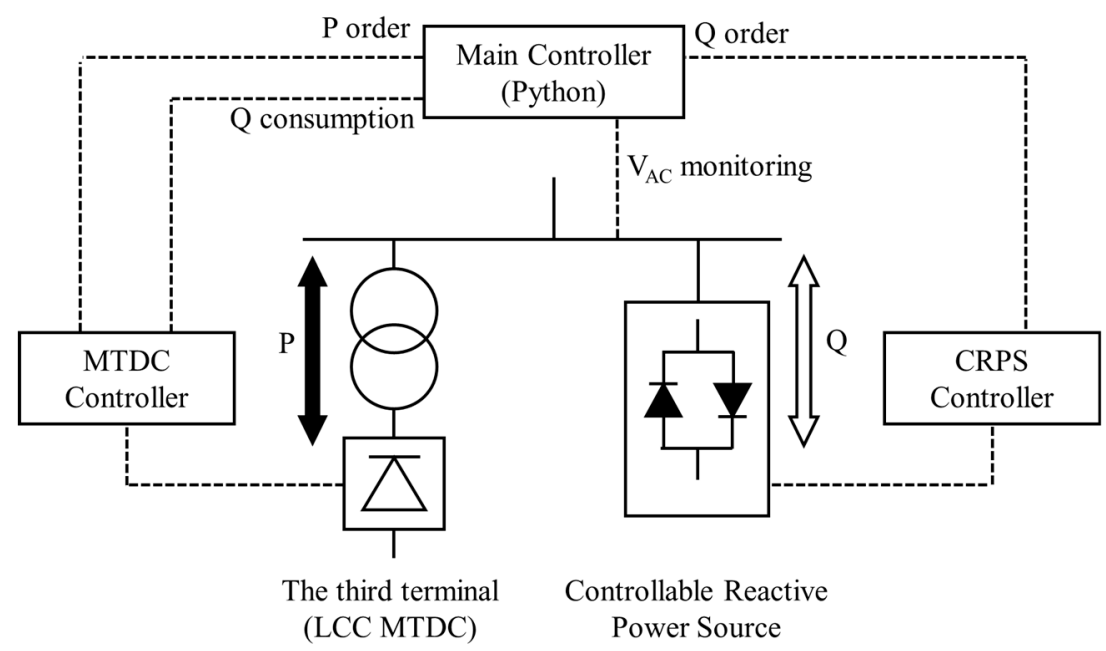

Figure 3. VSC terminal model from the use of the MTDC and the Controllable Reactive Power Source (CRPS).

The reactive power supply, however, is generally limited by the critical frontier, maximum voltage, and current limitation [34]. Figure 4 a describes the operation range sample of the VSC. A simplified operation range was applied in this paper, as shown in Figure 4 b. The per unit (p.u.) value is based on the rated converter capacity. 


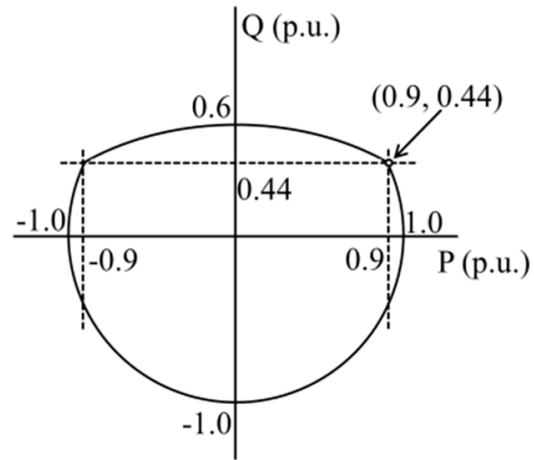

(a)

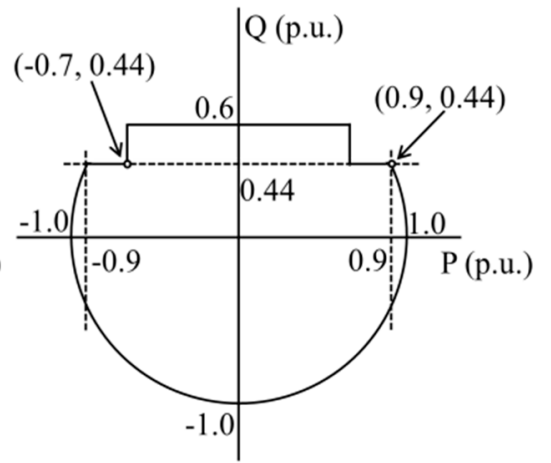

(b)

Figure 4. VSC operation range limitation: (a) Sample of actual operation limitation; (b) simplified operation limitation.

The VSC operation range shown in Figure $4 \mathrm{~b}$ is constrained by the active power order and can be defined by Equations (1) to (3), as follows:

$$
\begin{gathered}
-\sqrt{S^{2}-P^{2}} \leq Q \leq \sqrt{S^{2}-P^{2}}(P \geq 0.9 \times S), \\
-\sqrt{S^{2}-P^{2}} \leq Q \leq 0.44 \times S(0.9 \times S>P \geq 0.7 \times S), \\
-\sqrt{S^{2}-P^{2}} \leq Q \leq 0.60 \times S(0.7 \times S \geq P),
\end{gathered}
$$

where $S$ is the rated capacity of the converter and $P$ is the active power.

For the definition of the CRPS operation range, the reactive-power compensation, which was consumed by the LCC MTDC, was considered. Consequently, Equations (1)-(3) were modified to set the CRPS operation range, according to Equations (4)-(6).

$$
\begin{gathered}
-\sqrt{S^{2}-P^{2}}+Q_{d} \leq Q_{S T C} \leq \sqrt{S^{2}-P^{2}}+Q_{d}(P \geq 0.9 \times S), \\
-\sqrt{S^{2}-P^{2}}+Q_{d} \leq Q_{S T C} \leq 0.44 \times S+Q_{d}(0.9 \times S>P \geq 0.7 \times S), \\
-\sqrt{S^{2}-P^{2}}+Q_{d} \leq Q_{S T C} \leq 0.60 \times S+Q_{d}(0.7 \times S \geq P),
\end{gathered}
$$

where $Q_{d}$ is the consumed reactive power of the converter and $Q_{S T C}$ is the CRPS output. For the selection of the CRPS maximum output, the LCC MTDC active power capacity was employed.

\subsection{Dynamic Model of the Hybrid MTDC}

The LCC MTDC dynamic model and the CRPS dynamic model were used for the dynamic simulation as well. The MTDC model controlled the active power and the CRPS model compensated for and controlled the reactive power. Generally, the current limitation of an MTDC model converter is lower for the normal operation, due to the ripple of the DC current; however, the DC current lower limit was set as zero for the proposed hybrid MTDC model, owing to the simulation of the situation wherein the power flow direction was changed dynamically.

The CRPS model parameters reflect the current limitation. The capacitive current limitation and the inductive current limitation can be set individually, and the current limitation means the operation range. The reactive power consumption was considered for the CRPS operation range. In contrast to the steady state, the reactive power consumption continually changes in the dynamic simulation, along with the active power change. The CRPS operation range should therefore continue changing during the simulation. In this paper, the main controller is proposed and the controller changes the parameters for CRPS. The dynamic simulation has a time step, and the dynamic system status is calculated at each step. The main controller connects two generic model controllers of LCC MTDC and CRPS, thus, 
the third terminal is operated as one device. Active and reactive power order is defined in the main controller and limitation as well.

For the CRPS operation range, the reactive power consumption was calculated, and the controller changed the CRPS current limitation between the time steps. The inductive current limitation is the same, irrespective of the active power output, as described in Equation (7). Meanwhile, the capacitive current limitation should be selected by the active power output of the LCC. The current limitations according to the active power output are represented in Equations (8) to (10), as follows:

$$
\begin{gathered}
I_{L, \text { limitation }}=\sqrt{S^{2}-P^{2}}-Q_{d}, \\
I_{C, \text { limitaion }}=\sqrt{S^{2}-P^{2}}+Q_{d}(P \geq 0.9 \times S), \\
I_{C, \text { limitaion }}=0.44 \times S+Q_{d}(0.9 \times S>P \geq 0.7 \times S), \\
I_{C, \text { limitaion }}=0.60 \times S+Q_{d}(0.7 \times S \geq P),
\end{gathered}
$$

where $I_{L \text {,limitation }}$ is the inductive current limitation and $I_{C \text {,limitation }}$ is the capacitive current limitation.

Even though the CRPS operation range was modified at every time step, it is likely that the sum of the LCC reactive power consumption and the CRPS output is in the operation range of the VSC reactive power. Therefore, the active power order is transfer to the MTDC controller and the amount of reactive power consumption is calculated. The main controller defines the reactive power order, considering AC voltage and the reactive power consumption. To make the reactive power output meet the order value, CRPS limitation parameters are changed by the main controller. The order calculation and parameters changing are performed at every time step. The block diagram for the dynamic model operation is shown in Figure 5.

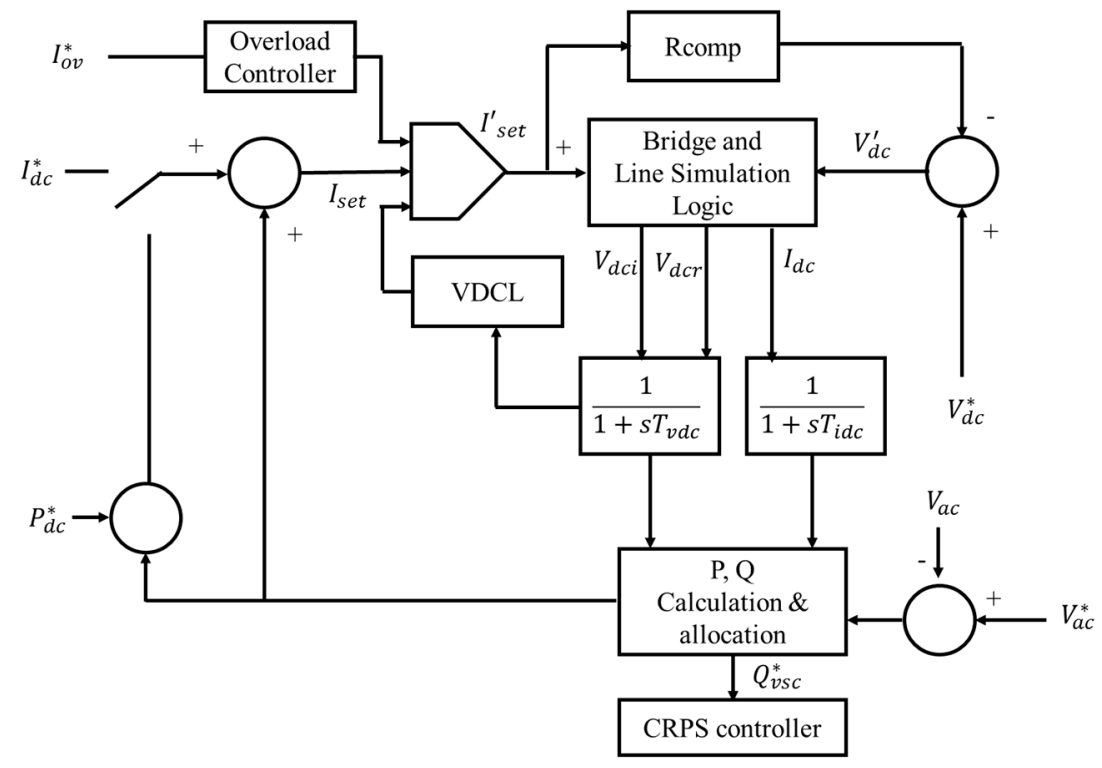

Figure 5. Block diagram of the dynamic model for the hybrid MTDC.

\subsection{Model Verification}

The proposed hybrid MTDC model was verified through the dynamic simulation. The performance of the VSC reactive power control was observed in terms of the reactive power control for the AC bus voltage. The VSC rated capacity was set as 500 MVA, and a disturbance (bus fault) was applied at the VSC station to verify the reactive power operation range. The different CRPS operation ranges are compared in Figure 6, and the active power outputs of the VSC with respect to each of their rated capacities are $450 \mathrm{MW}, 350 \mathrm{MW}$, and $200 \mathrm{MW}$. The CRPS capacitive output should be limited 
by Equations (8) to (10) at each time step. The analysis of the VSC reactive power outputs for each active power case for which the LCC consumption capacity and the CRPS output were considered are presented in Figure 7. As shown in Figure 6, CRPS outputs were limited by Equations (8) to (10), considering $Q_{d}$ at each time step. Consequently, the limitation value was changed for each step. However, the VSC reactive power outputs were limited in the operation range shown in Figure 4, thus the limited output is fixed, as shown in Figure 7.

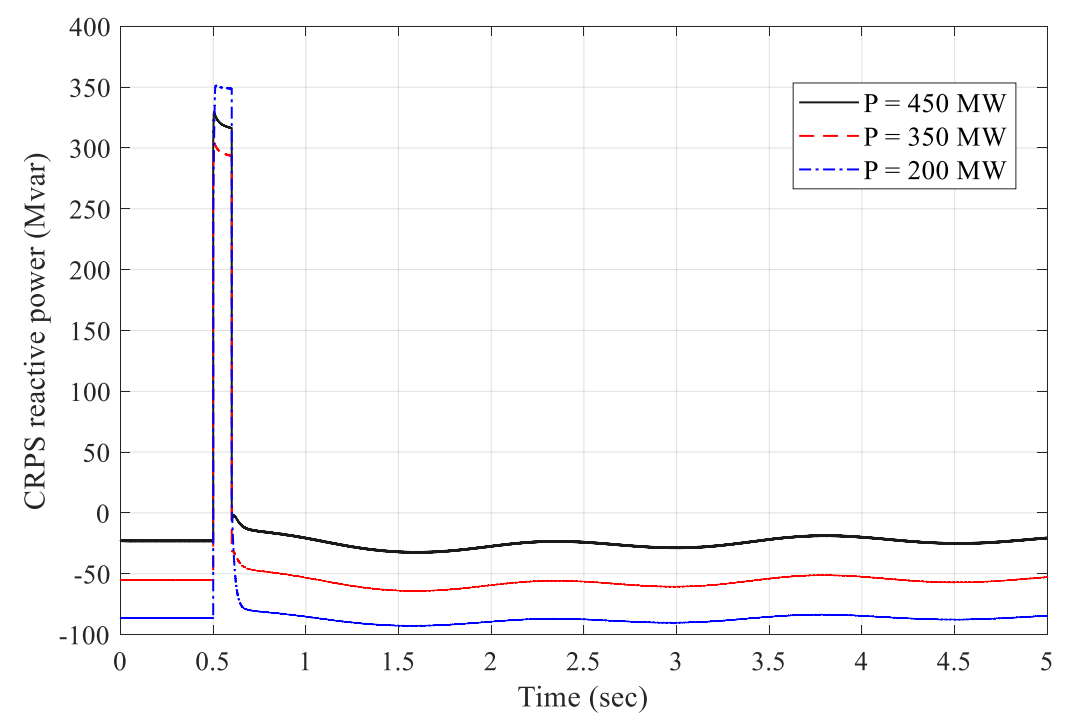

Figure 6. CRPS reactive power output by the different active power outputs of the VSC.

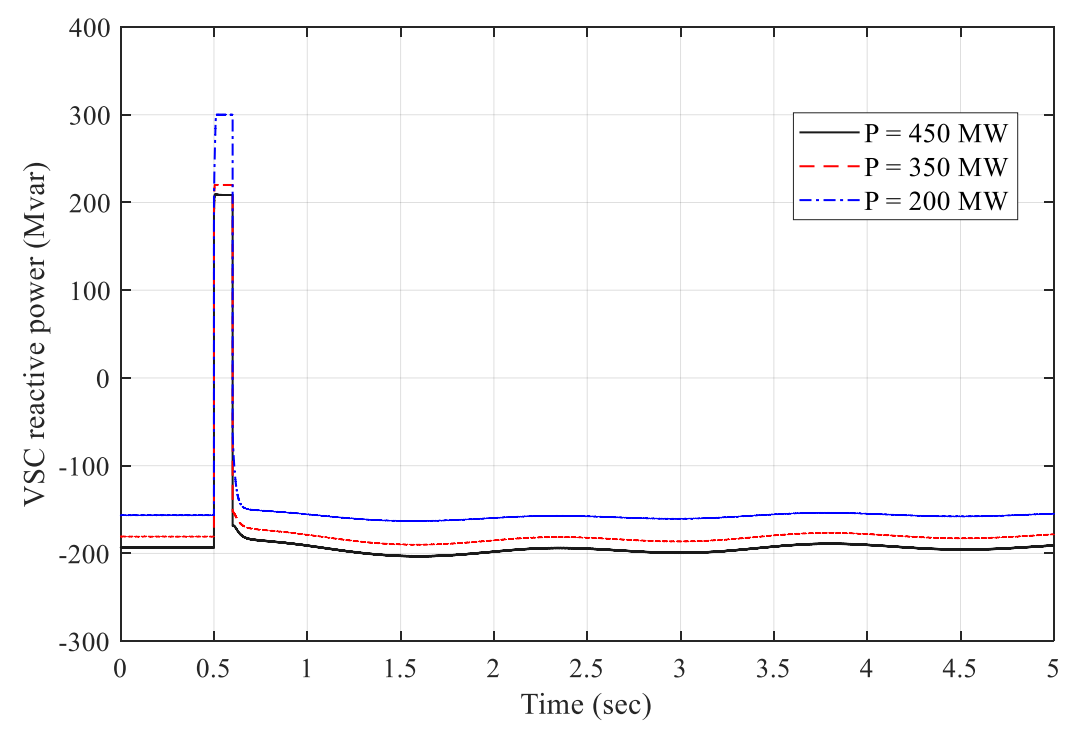

Figure 7. VSC reactive power output by the different active power outputs of the VSC.

When the active power output is 0.4 p.u., the limitation of the reactive power output, modeled according to Equation (3), is 3 Mvar and corresponds to the rated capacity of 0.6 p.u. The limitations of the reactive power outputs of the other cases were modeled according to Equations (1) and (2).

The active power change was simulated to verify the dynamic flow direction change. The VSC was proposed to change the power flow dynamically in the transient status, but the active power of the VSC changes with a delay, even if the power order is switched from the original value to the new order value as a step function [35]. For this reason, the time constant for the power output delay was applied in the model. As presented in Figure 8, the active power order changed at $0.5 \mathrm{~s}$ in the simulation. The active power of the VSC changed from a positive value to a negative value with the applied delay. 
Therefore, the VSC operated the inverter mode at the beginning, but the mode changed to the rectifier mode. The changed active power amount was taken by the LCC inverter of the hybrid MTDC system.

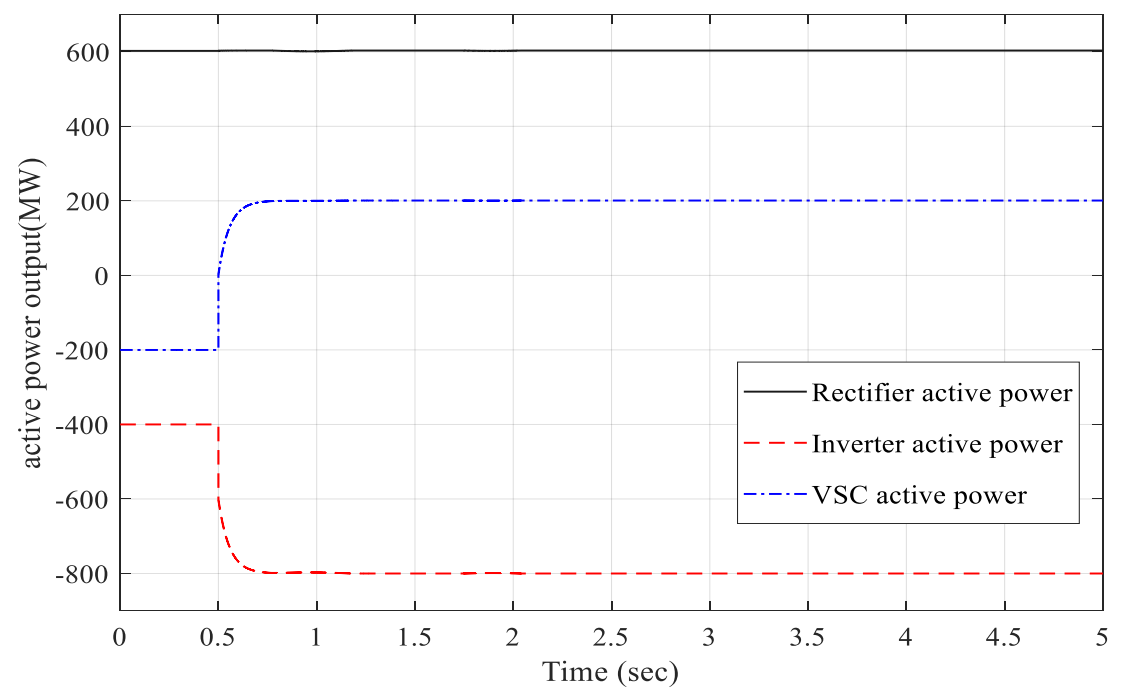

Figure 8. The active power for each converter.

Verified through the simulations, the proposed model is an approximate model that is focused on the following two features: AC bus voltage control and power flow direction change.

The VSC can control the reactive power in a defined operation range to maintain the AC bus voltage with the proposed model. The converter can also control the active power dynamically, even with the flow direction. Therefore, the hybrid MTDC model was used for the evaluation of the operation strategy.

\section{Evaluation of the Proposed Operation Strategy}

The operation strategy for the hybrid MTDC system is proposed in this paper. The proposed DC system was extended from a point-to-point (PTP) HVDC system and the extended terminal consists of the VSC. The modeling method for which the LCC MTDC and CRPS models are used for the hybrid MTDC was studied and verified.

The control scheme of the proposed operation strategy is described in Figure 9. When the event occurs at the parallel AC lines, the hybrid MTDC system will get a signal from the grid operator. The active power order is calculated depending on the fault location, while the reactive power order is calculated depending on the operation range of the VSC by Equations (1)-(3). The reactive power limitation for CRPS is calculated by Equations (7)-(10) as well. If the system considers the overload operation, the active power order will be overwritten by the overload factor, which defines the overloading percentage while the power order for LCC converters is calculated. The calculated power order for the converters is transferred to the main controller. 


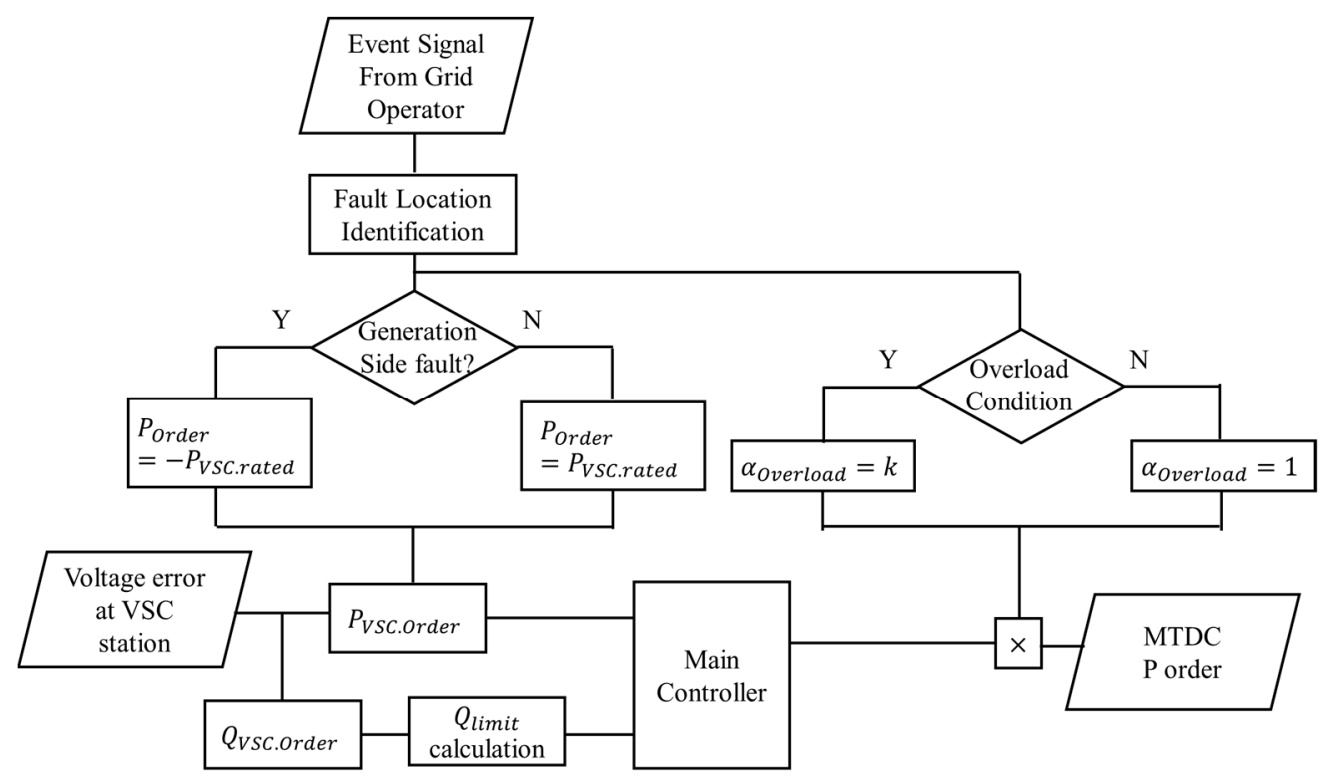

Figure 9. Control algorithm of the proposed operation strategy.

The simulations were performed to evaluate the operation strategy for the extended DC system, and they were compared with the PTP HVDC and LCC MTDC topologies. The PTP HVDC was applied to the IEEE 39 bus test system and the DC transmission system was extended to the LCC MTDC. In addition, the proposed modeling method was applied at the third terminal of the LCC MTDC system to compose the hybrid MTDC system. The applied PTP HVDC and LCC MTDC operation characteristics are indicated in Figure 10. The DC current was controlled by the rectifier, and the inverter controlled the DC voltage for both the PTP HVDC and LCC MTDC systems. The extended terminal can be operated as the rectifier and the inverter, and the current control mode was applied to the converter. The Voltage Dependent Current Order Limitation (VDCOL) was applied to the current control converters. The third terminal, however, is the VSC in the case of the hybrid MTDC, and therefore, the operation characteristic was changed, as shown in Figure 11, and the VDCOL function was removed from the third terminal.

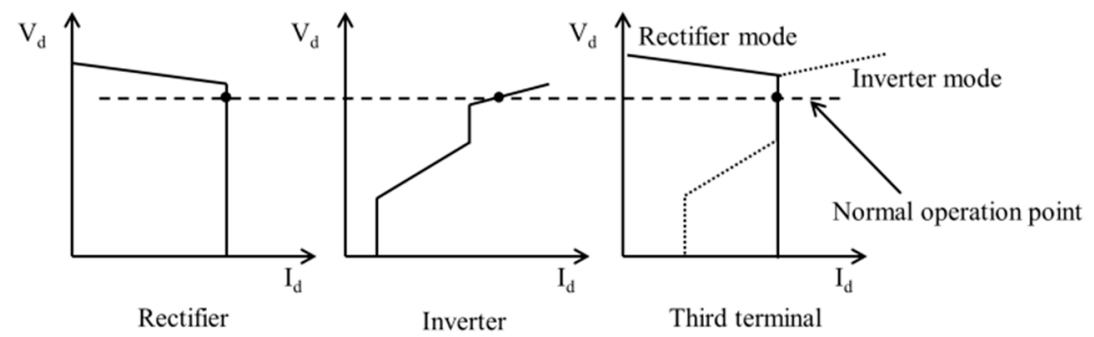

Figure 10. Line Commutate Converter (LCC) MTDC operation characteristics.

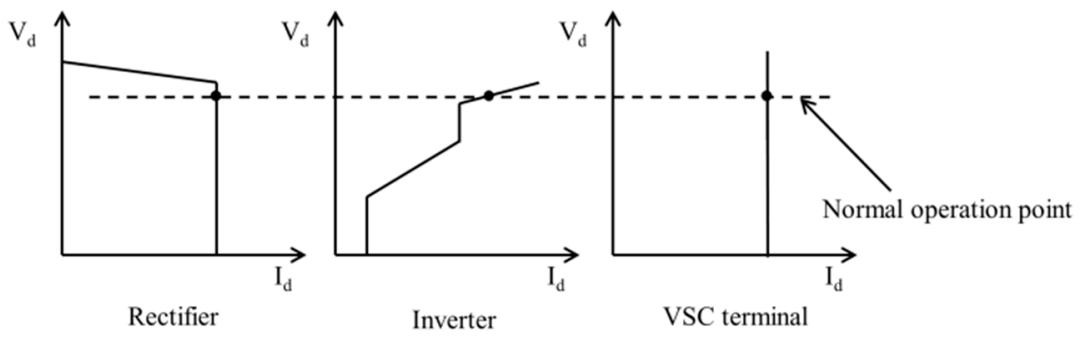

Figure 11. Hybrid MTDC operation characteristics. 
The topologies of the DC transmission system were applied to the IEEE 39 bus test system, and the system was modified to comprise generation and load areas. In the test system, the PTP HVDC system was applied from bus 22 to bus 4 . The extended terminal was composed at bus 17 . The route of the AC transmission line from bus 16 to bus 3 is the parallel line for the transfer of the power between the areas. The modified system is represented in Figure 12.

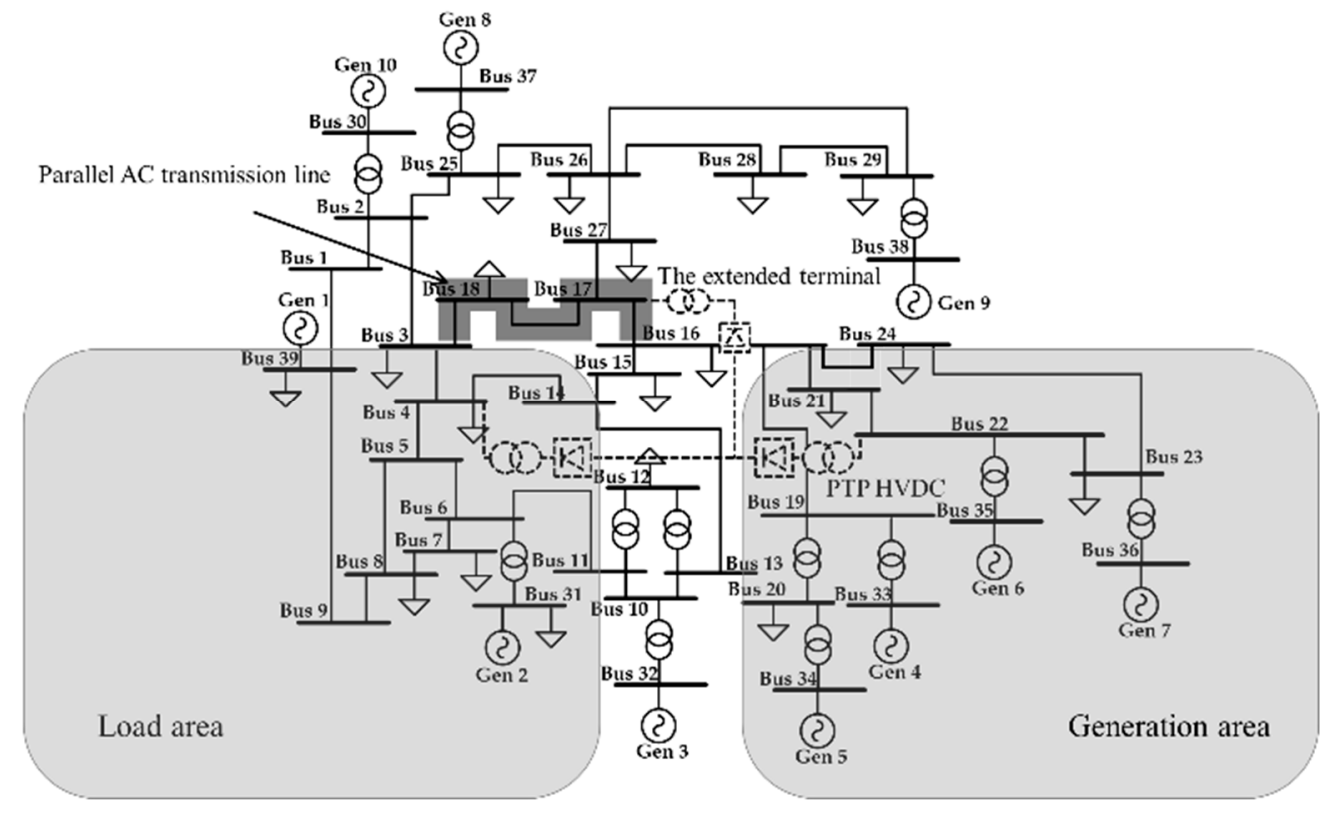

Figure 12. Modified IEEE 39 bus test system and the applied DC system.

\subsection{Utilization of the Parallel AC Transmission Line}

The utilizations of the parallel AC transmission line were evaluated through the performance of a steady state calculation for each topology. The third terminal was operated as the inverter to provide the active power to the AC lines. The transmission power capacities are $600 \mathrm{MW}$ for the rectifier, 400 MW for the inverter, and $200 \mathrm{MW}$ for the third converter. The analysis results are indicated in Table 1. Line 1 is from bus 16 to bus 17, line 2 is from bus 17 to bus 18 , and line 3 is from bus 18 to bus 3 . The third terminal provided the active power for bus 17, thereby increasing the power flows of lines 2 and 3 for the MTDC topologies. Even though the power flow of line 1 decreased, the total power flow amount through the AC line increased. Therefore, the utilization of the parallel AC line increased. Table 2 indicates the results of the power flow calculation for the cases where the active power output of the third terminal is $400 \mathrm{MW}$. As the output of the third terminal was increased, the utilization of line 1 decreased and the utilizations of lines 2 and 3 increased.

Table 1. Parallel alternating current (AC) transmission line power flow results of the third terminal 200 MW output.

\begin{tabular}{ccccc}
\hline CASE & Line 1 (MW) & Line 2 (MW) & Line 3 (MW) & Total (MW) \\
\hline PTP HVDC & 232.64 & 183.73 & 25.49 & 441.86 \\
LCC MTDC & 149.46 & 257.90 & 117.37 & 542.73 \\
Hybrid MTDC & 148.88 & 273.74 & 115.23 & 537.85 \\
\hline
\end{tabular}


Table 2. Parallel AC transmission line power flow results of the third terminal $400 \mathrm{MW}$ output.

\begin{tabular}{ccccc}
\hline CASE & Line 1 (MW) & Line 2 (MW) & Line 3 (MW) & Total (MW) \\
\hline PTP HVDC & 232.64 & 183.73 & 25.49 & 441.86 \\
LCC MTDC & 67.08 & 368.00 & 209.10 & 644.18 \\
Hybrid MTDC & 66.53 & 366.01 & 207.11 & 639.65 \\
\hline
\end{tabular}

Regarding the extended DC system, the total utilization of the parallel AC line can be controlled by the third terminal active power output. The hybrid MTDC can control the rate using the AC voltage control as well. However, due to the decrease of the load of the AC lines between the third terminal and the generation area, the appropriate third terminal output should be considered at the operation planning stage.

The utilization of the parallel AC transmission line is improved by $20 \%$ for $200 \mathrm{MW}$ output and $45 \%$ for $400 \mathrm{MW}$ output.

\subsection{Transient Stability Improvement}

Dynamic simulations were implemented to evaluate the transient stability of the power system with the hybrid MTDC. The proposed operation strategy is for the improvement of the AC line utilization, including the post-transient status.

In the case of the parallel AC line trip, the third terminal can provide or take the power from the usable AC lines, as shown in Figure 2. To evaluate the effect of the extended DC system, dynamic simulations were performed with the proposed model in Section 3 for two scenarios. The first scenario is an event at the AC line of the generation side, and the second scenario is an event at the load side.

The third terminal power flow direction changed after the event occurred in the proposed operation strategy. To utilize the usable AC line, the third terminal was operated in the inverter mode after the generation side event. To consider a severe case, the initial operation mode of the third terminal served as a rectifier and the output was $200 \mathrm{MW}$ in the first scenario. Figures 13-15 show the simulation results for the event. The active power output for each converter is represented in Figure 13 for the cases with the operation strategy. Figures 14 and 15 show the angle spread of the power system and the AC voltage of the inverter station.

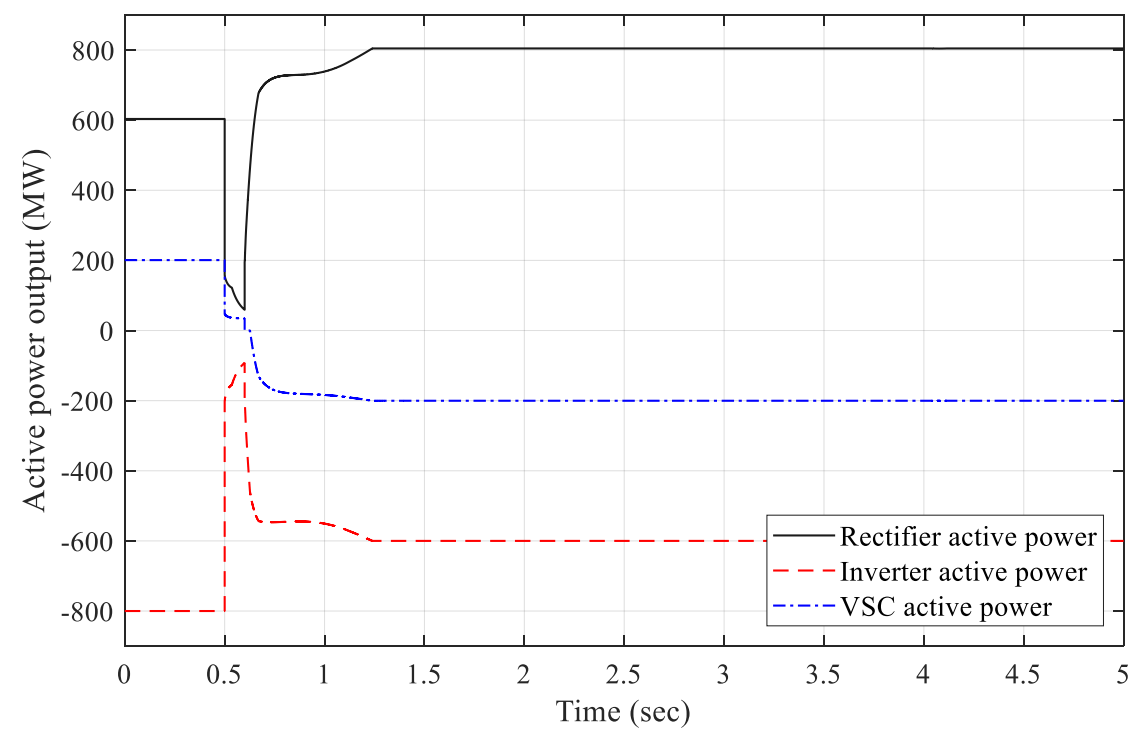

Figure 13. The active power output for each converter for the generation side event with the operation strategy. 


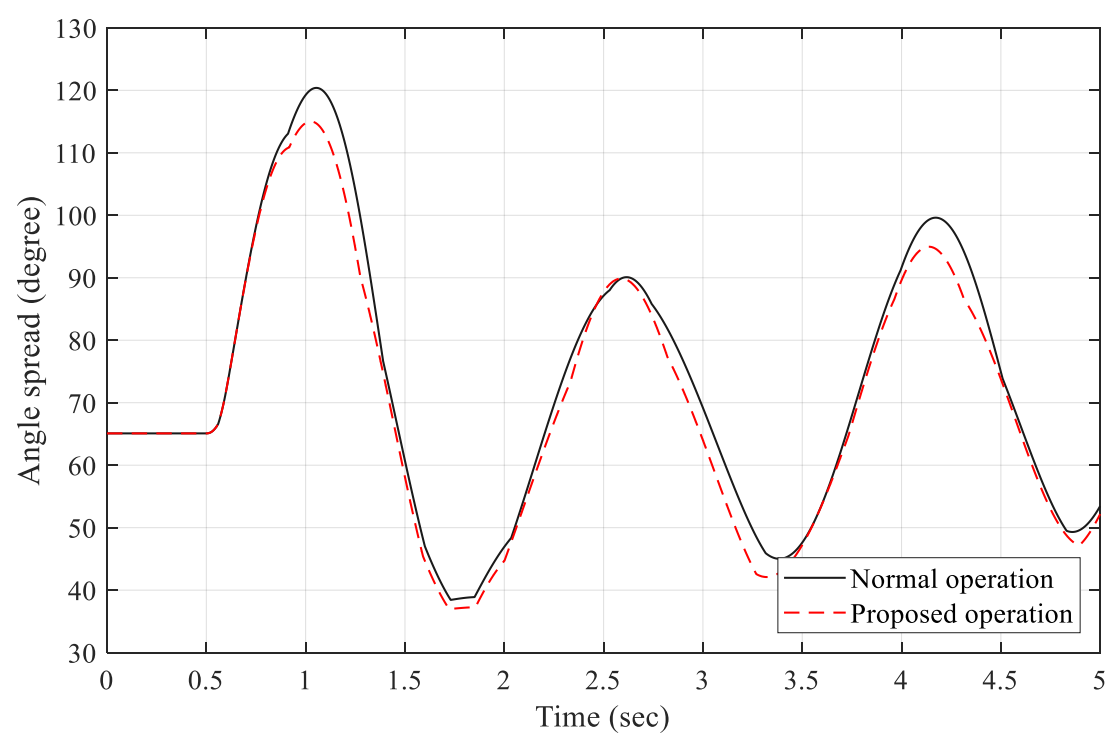

Figure 14. The angle spread for the generation side event.

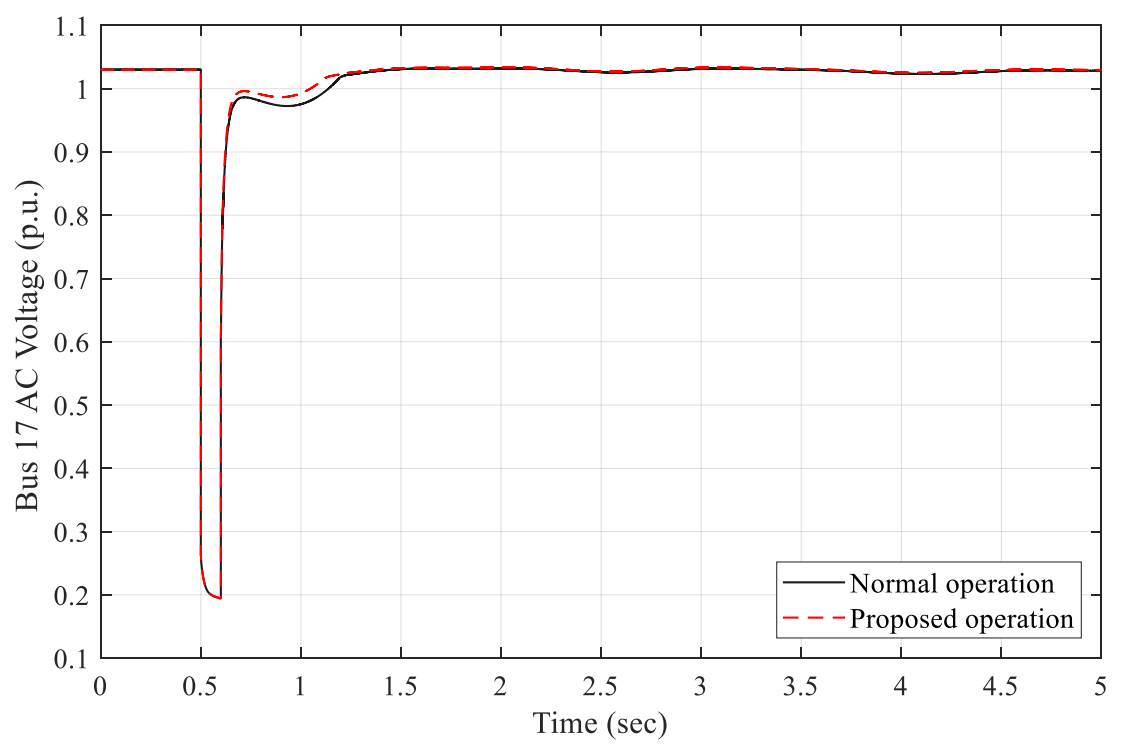

Figure 15. The AC voltage of the inverter station for the generation side event.

As shown in Figure 13, the total power exchange amount is the same, irrespective of the operation strategy; that is, the load area received the same amount of power. The transient stability was improved in Figure 14, even though the power exchange amount between the two areas was the same.

The angle spread is one of the indices that is used to evaluate the transient stability, especially the angle stability. The system is more stable during the transient status if the maximum angle spread value is smaller. The maximum angle spread of the case without the operation strategy is 120.38 degrees; however, with the operation strategy, the value decreased to 115.01 degrees. The voltage recovery feature of the load area was improved, as shown in Figure 15; therefore, the operation strategy improved the transient stability of the system.

Simulation results of the second scenario are represented in Figures 16-18. Figure 16 indicates the active power output of each converter for the cases with and without the operation strategy, and Figure 17 shows the angle spread from the load side event simulation results. The voltage recovery feature of the load area was improved, as shown in Figure 18. In the case of the second scenario, the generation side voltage recovery feature was improved, due to the operation strategy. 


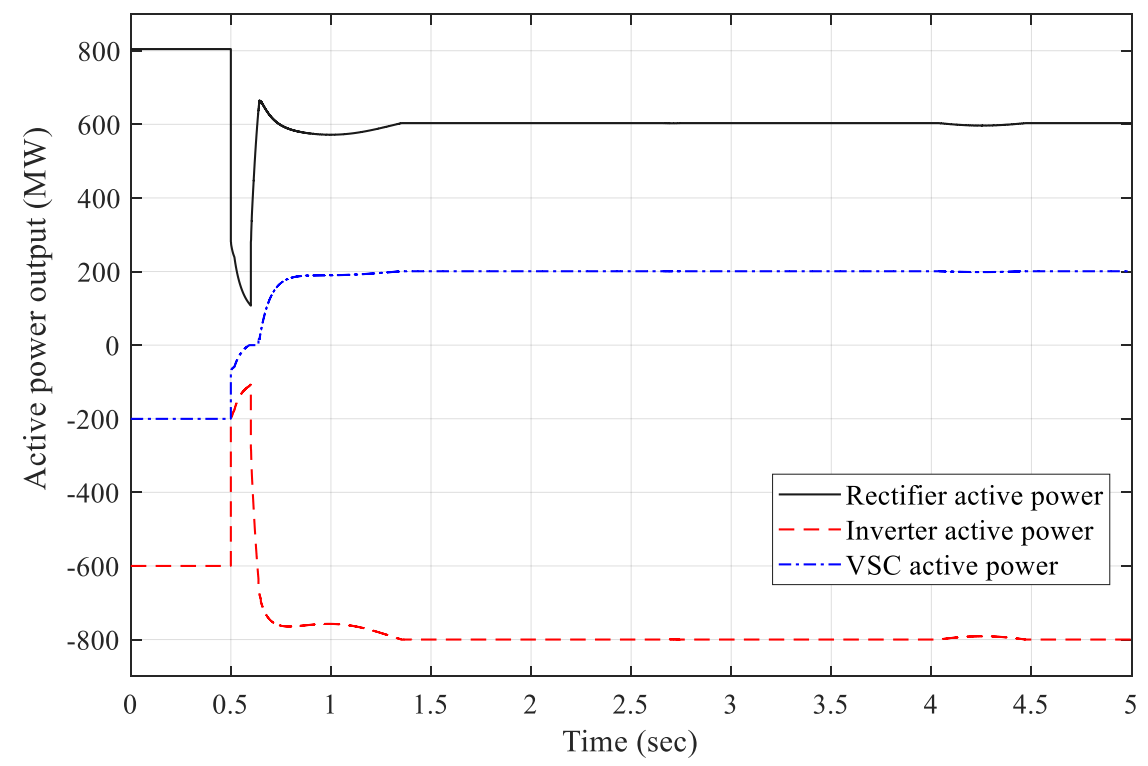

Figure 16. The active power output for each converter for the load side event with the operation strategy.

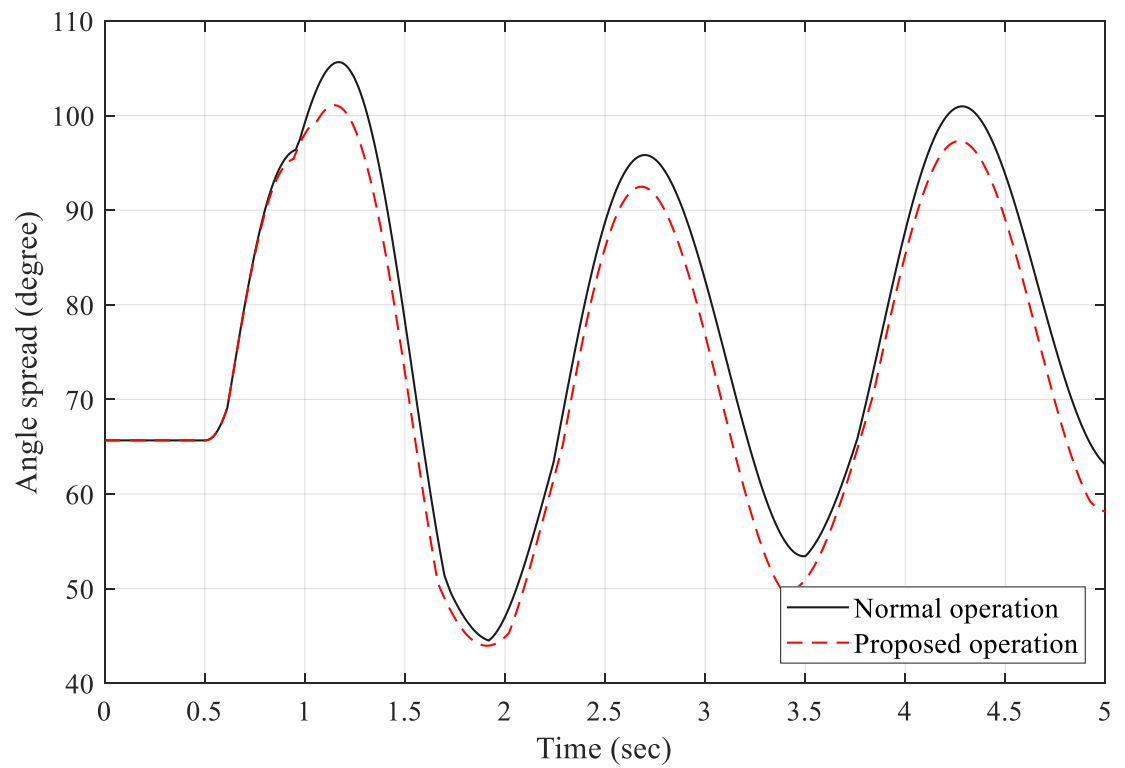

Figure 17. The angle spread for the load side event. 


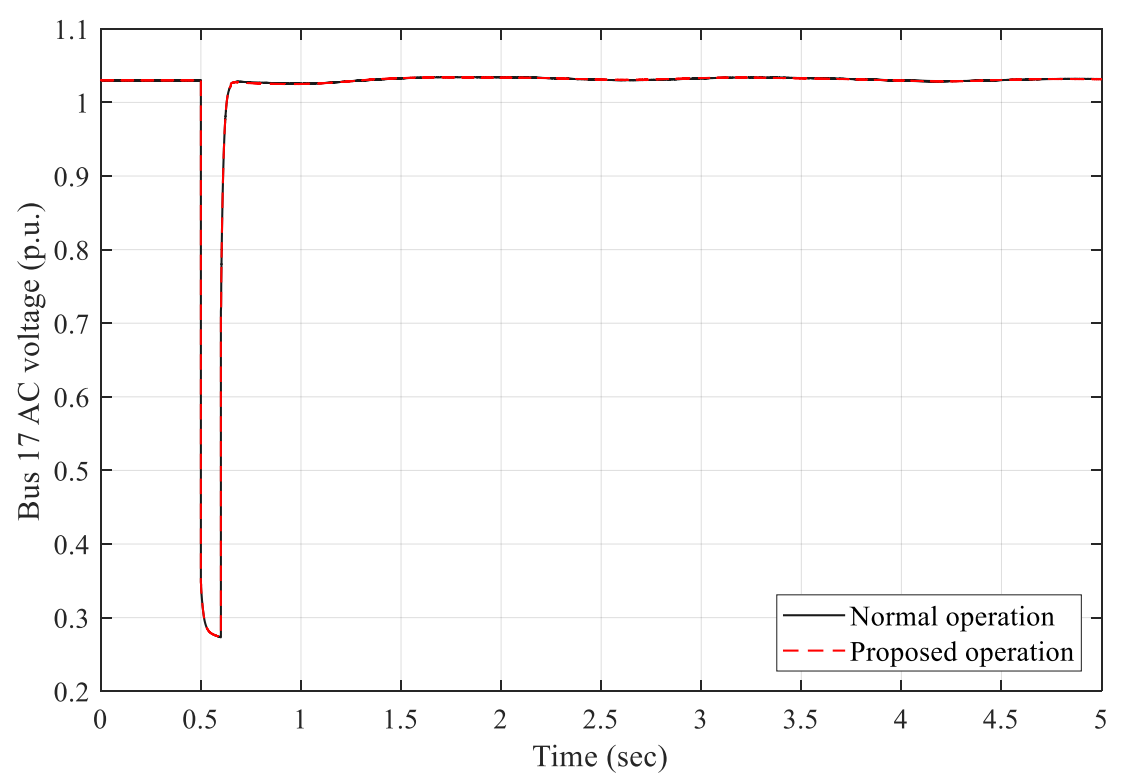

Figure 18. The AC voltage of the inverter station for the load side event.

In the load side event simulation, the VSC initial operation mode is an inverter mode for the consideration of a severe event case, and the active power output is also $200 \mathrm{MW}$. In the second scenario, the transient stability was improved as well, even though the effect is relatively low. The maximum value of the angle spread decreased from 105.64 degrees to 101.08 degrees.

Although the effect of the transient stability improvement is small for the test system, due to the scale of the system and the DC transmission also being small, the effect is expected to increase for the larger scales of the power system and the DC transmission system.

\subsection{Overload Consideration}

The overload operation was considered for the proposed operation strategy in this paper. A temporary overload can initially mitigate the imbalance between the generation and the load area. The simplified overload simulation was performed for each topology. The event that causes voltage problems at the third terminal was considered. The AC voltage of the third terminal from the simulation results is represented in Figures 19 and 20 for the same event. The transient stability for the LCC MTDC case is unstable, as opposed to the hybrid MTDC because of the voltage stability of the third terminal. LCC HVDC cannot change the direction of power flow dynamically and requires more reactive power for overload, thus the power system transient stability would be worse for the event. As shown in Figure 20, only the overload case was stable.

A detailed overload simulation with the operation strategy was implemented for the hybrid MTDC topology, and the second scenario, which is the event at the load side, was simulated. The active power output from the simulation result is indicated in Figure 21. The inverter output was overloaded to $1000 \mathrm{MW}$; therefore, the temporarily provided load area is $200 \mathrm{MW}$ more than the original scenario. The surplus power mitigated the imbalance between the power and the load, thereby improving the transient stability. 


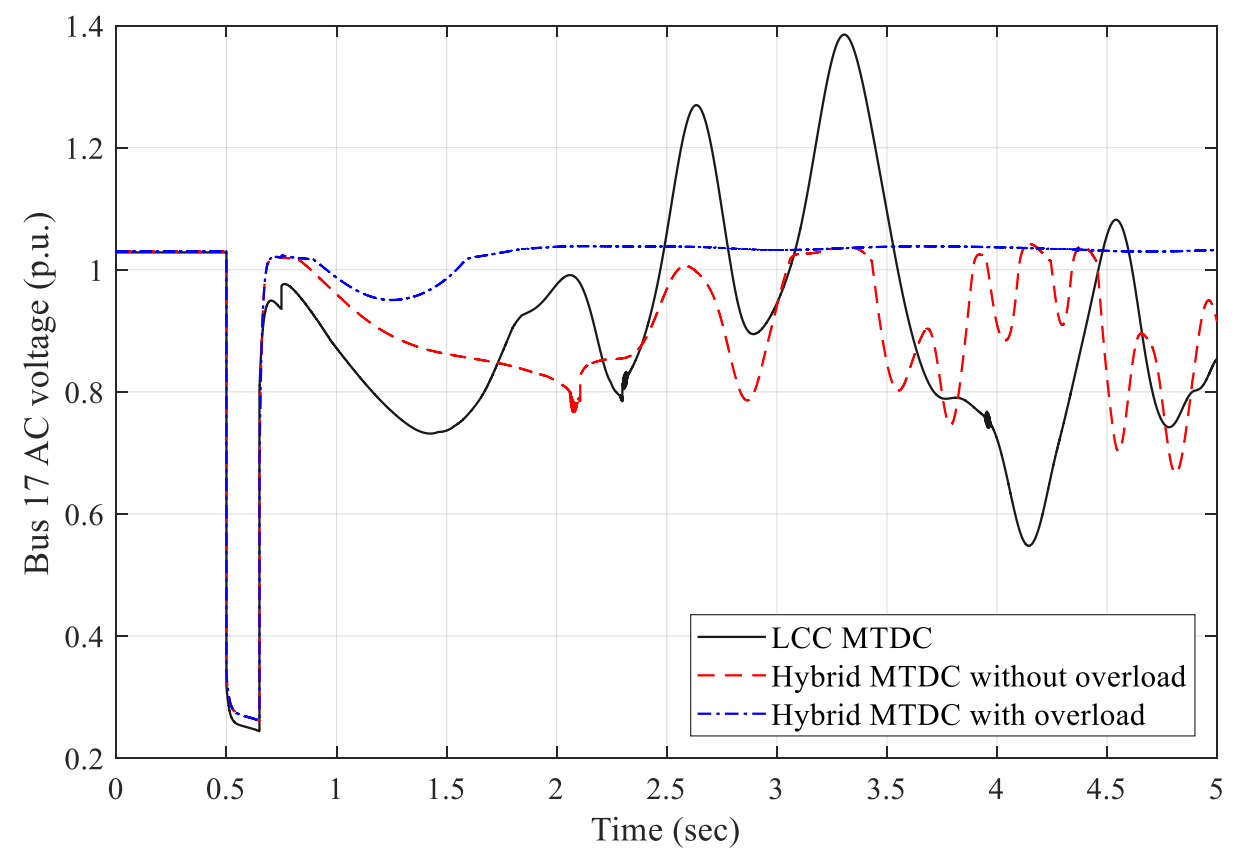

Figure 19. The AC voltage of third terminal from the simple overload simulation for each topology.

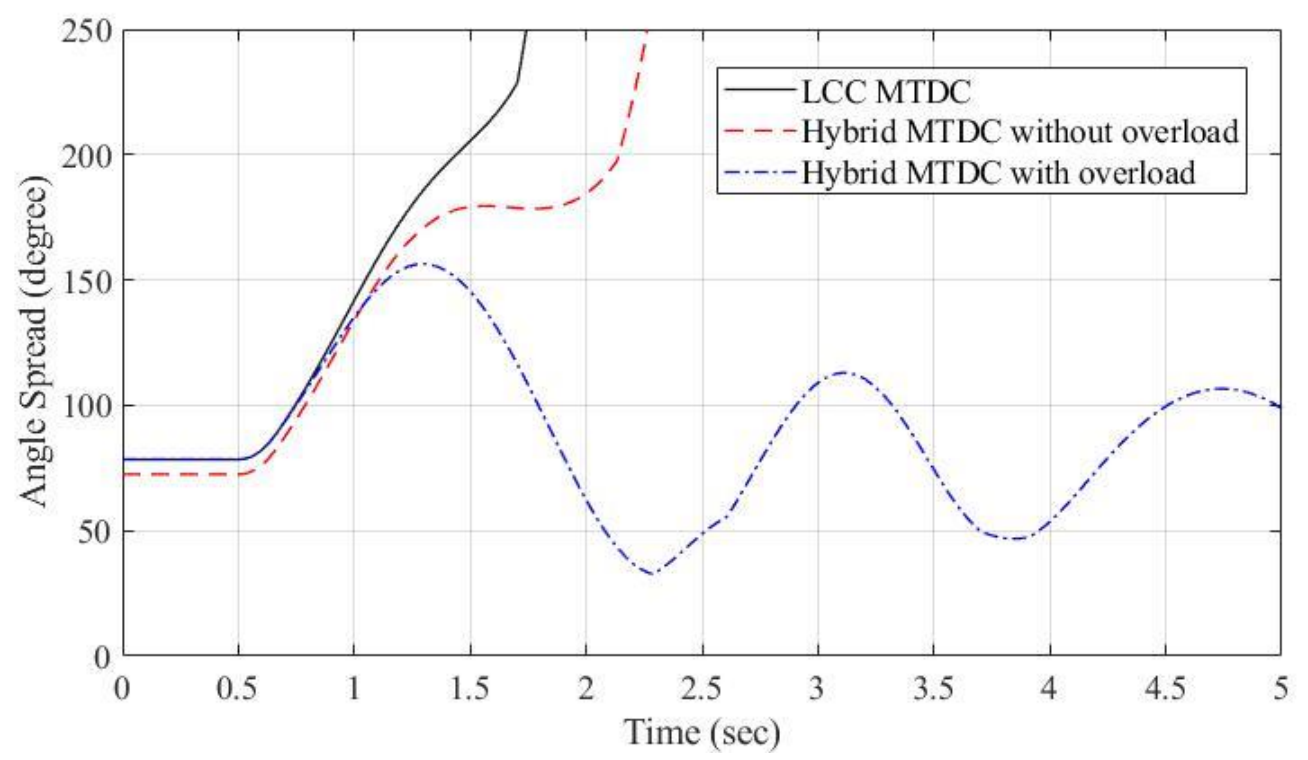

Figure 20. The angle spread from the simple overload simulation for each topology. 


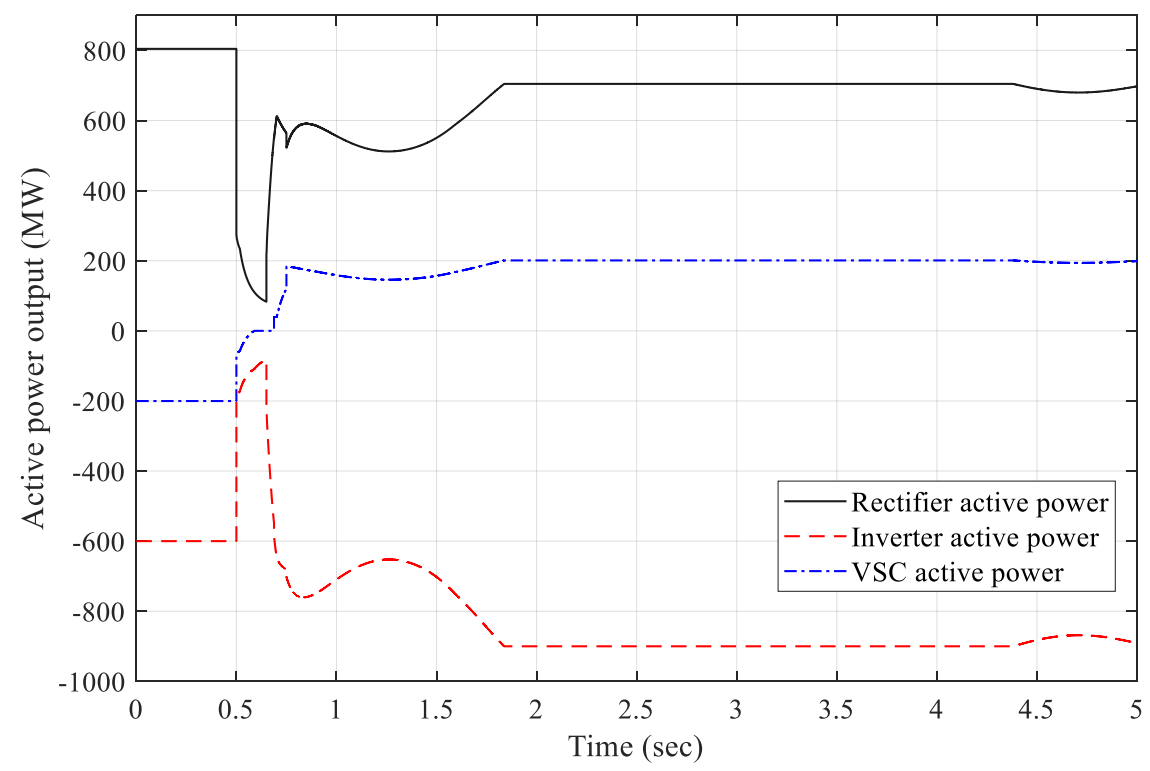

Figure 21. The active power output for each converter with the overload.

The effect of the transient stability improvement is expected to increase for the larger scales of the power system and the DC transmission system.

\section{Case Study of the Actual System Data}

The case study using the actual power system data, which is Korean power system data, was conducted. The hybrid MTDC system is applied in the 2024 planning data. The existing LCC HVDC systems are extended to the hybrid MTDC system and the $765 \mathrm{kV}$ transmission lines are the parallel AC transmission lines. Figure 22 is a simplified single line diagram of the hybrid MTDC system and the Korean power system near the MTDC.

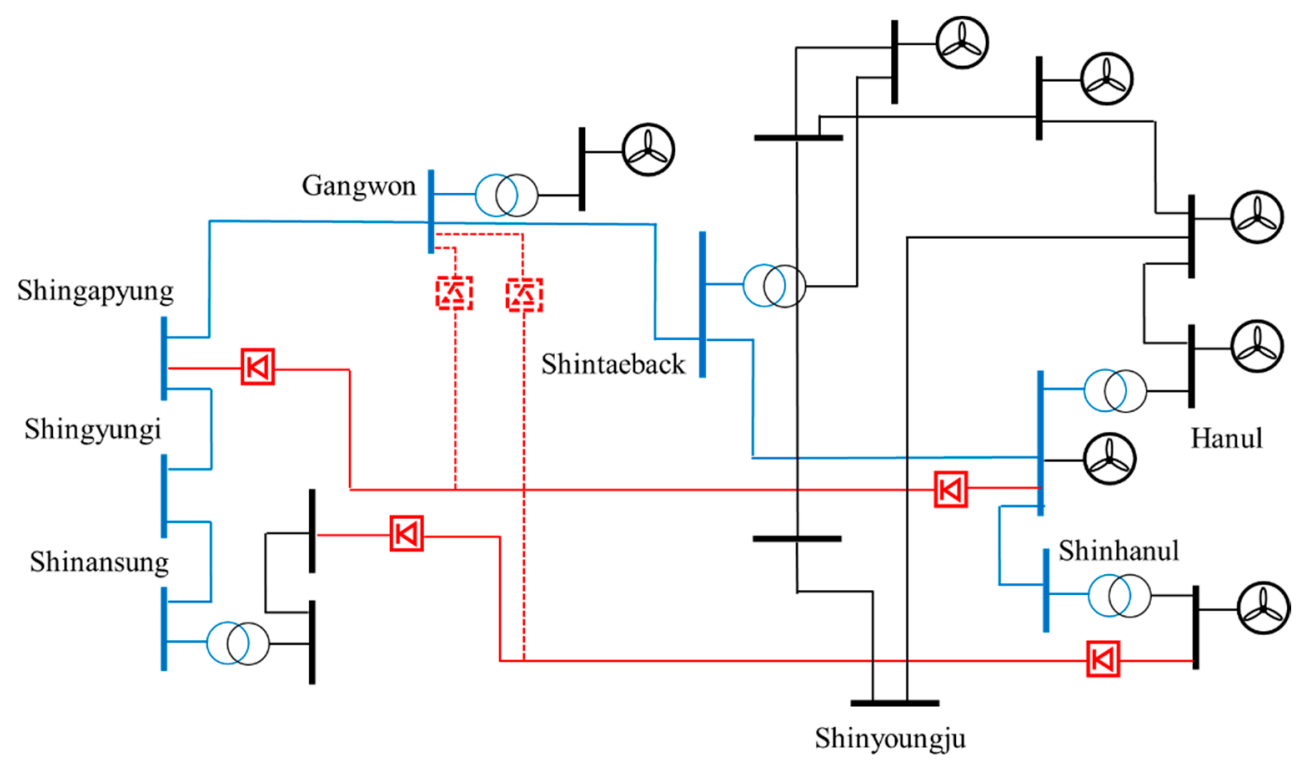

Figure 22. Actual power system data with the hybrid MTDC system.

The system has the generation area and the load area similar to the modified 39 bus system used in this paper. The east coastal area is a large-scale generation area and the generated power from the area is transmitted to the west metropolitan area of the system, which is the load area. The power 
system total load is approximately $102 \mathrm{GW}$, while the exiting LCC HVDC systems are two bipolar and the rated capacity is $8 \mathrm{GW}$. Furthermore, the HVDC system has an overload operation mode to $10 \mathrm{GW}$ and the available overload operation period is five seconds. The third terminal is connected to the parallel AC transmission line and the rated capacity is 600 MVA.

Dynamic simulations were conducted for the event at the load area and the stability improvement of the system by the operation strategy was compared. The simulation scenario for the load side event is as follows:

- $765 \mathrm{kV}$ bus fault at $0.5 \mathrm{~s}$;

- Clear fault after 5 cycles and trip branches (0.5833 s);

- Generator trip after 4 cycles $(0.65 \mathrm{~s})$;

- $\quad$ Thyristor Controlled Series Compensator (TCSC) Boost up and HVDC overload if required at $0.7 \mathrm{~s}$;

- $\quad$ Run until $10 \mathrm{~s}$.

The simulation results are shown in Figures 23 and 24, and the actual system stability with normal operation and with the operation strategy was evaluated.

In the case of an original power system with two-terminal LCC HVDC, a machine has to be tripped for stable operation of the system. However, the stable operation of the system is possible without the machine trip in the case of the hybrid MTDC system. The maximum angle spread of the two-terminal LCC HVDC case was 165.51 degrees with a machine trip. A hybrid MTDC system can stabilize the system without the machine trip in the same event, as shown in Figure 24, and the maximum angle spread was 182.58 degrees.

The overload operation was considered as well for the actual power system data because the existing LCC HVDC system had the overload operation mode. The simulation results of the overload operation cases are presented in Figures 25 and 26.

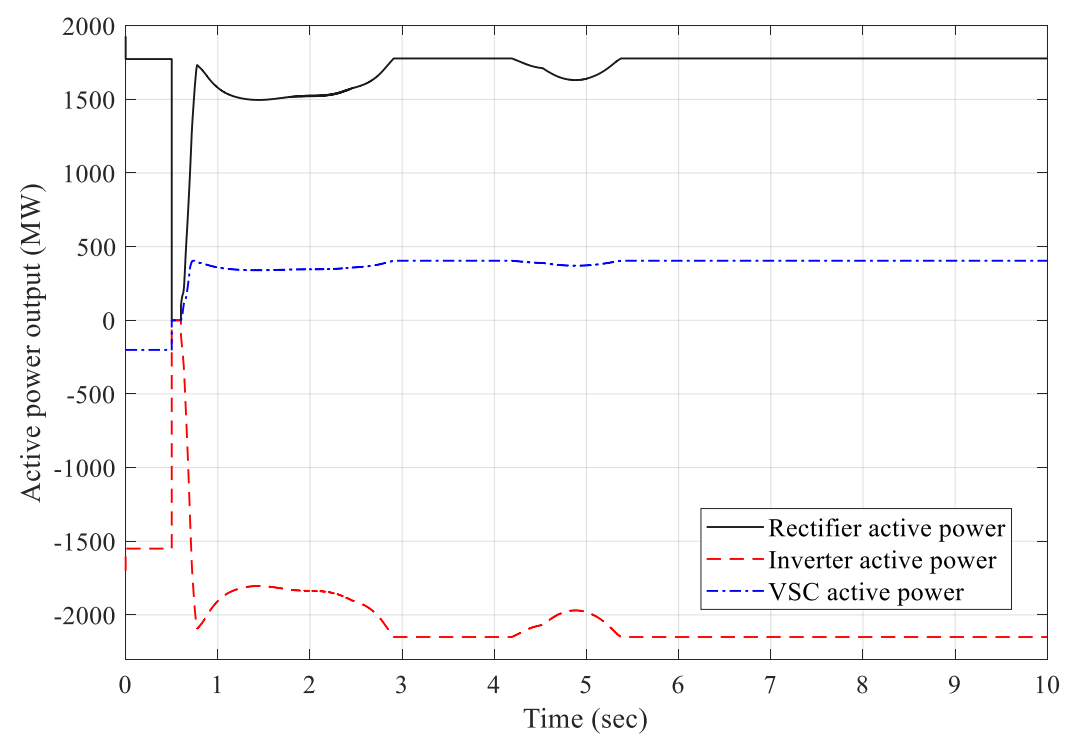

Figure 23. The active power output of each converter for the load side event with the operation strategy in the actual system data. 


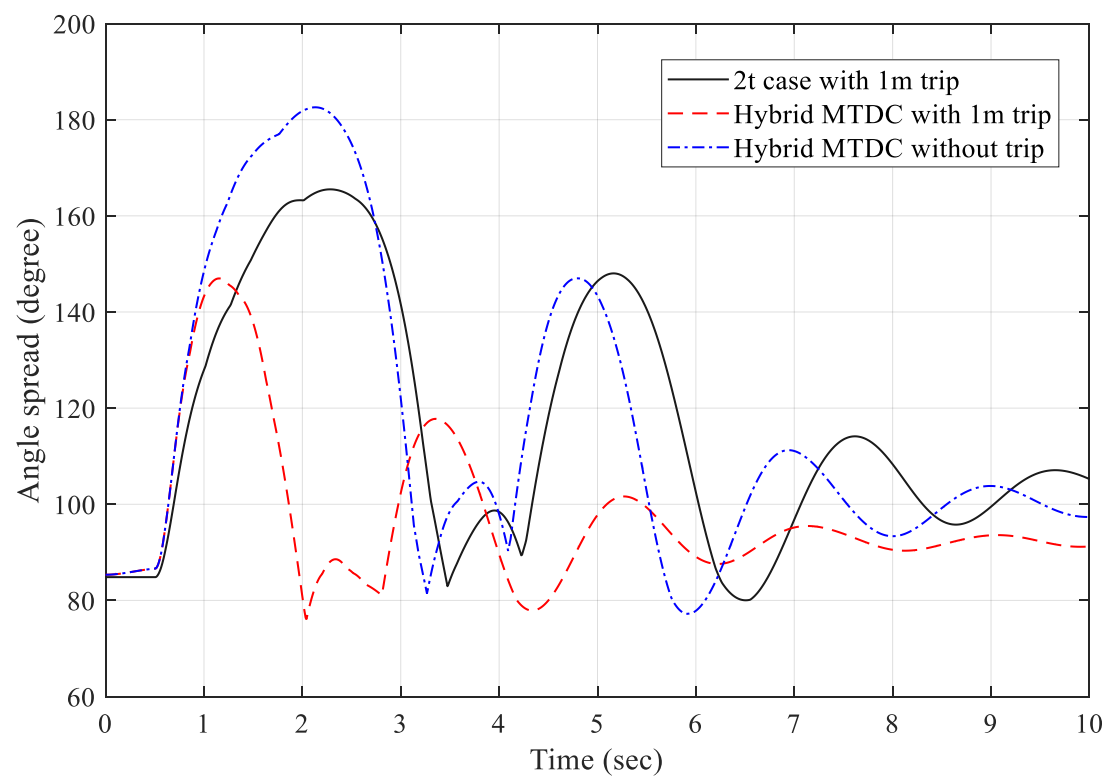

Figure 24. The system angle spread for the load side event in the actual system data.

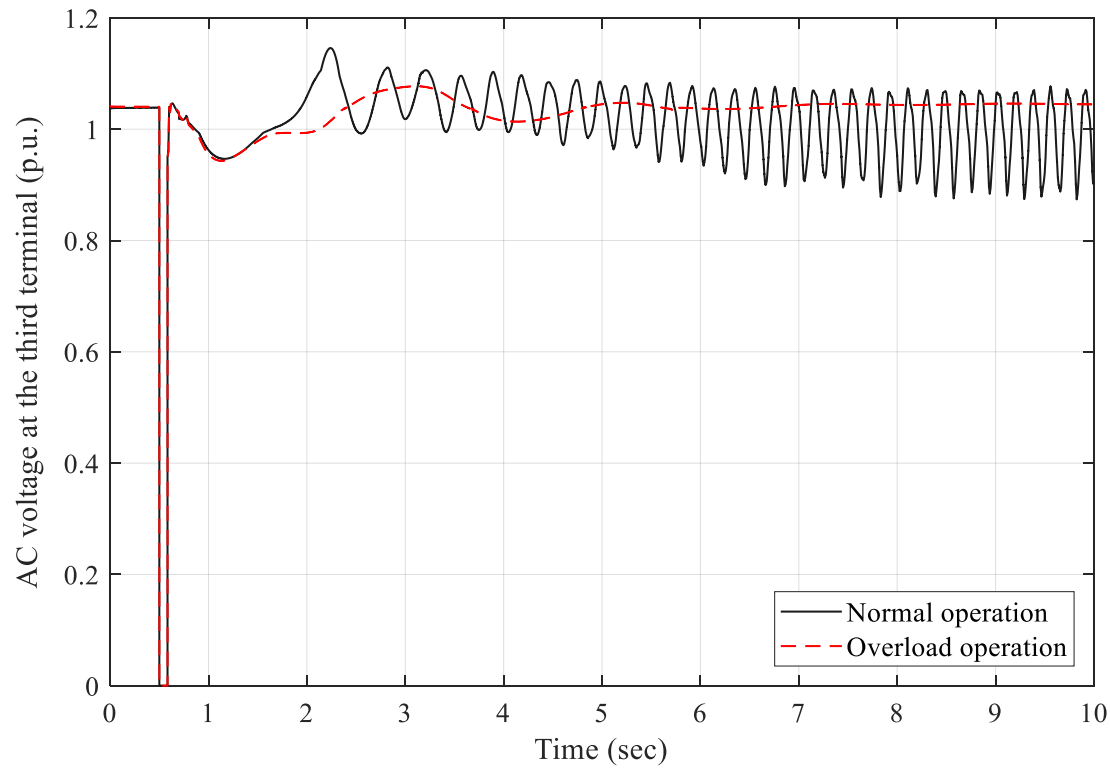

Figure 25. The AC voltage at the third terminal for each case in the actual system data. 


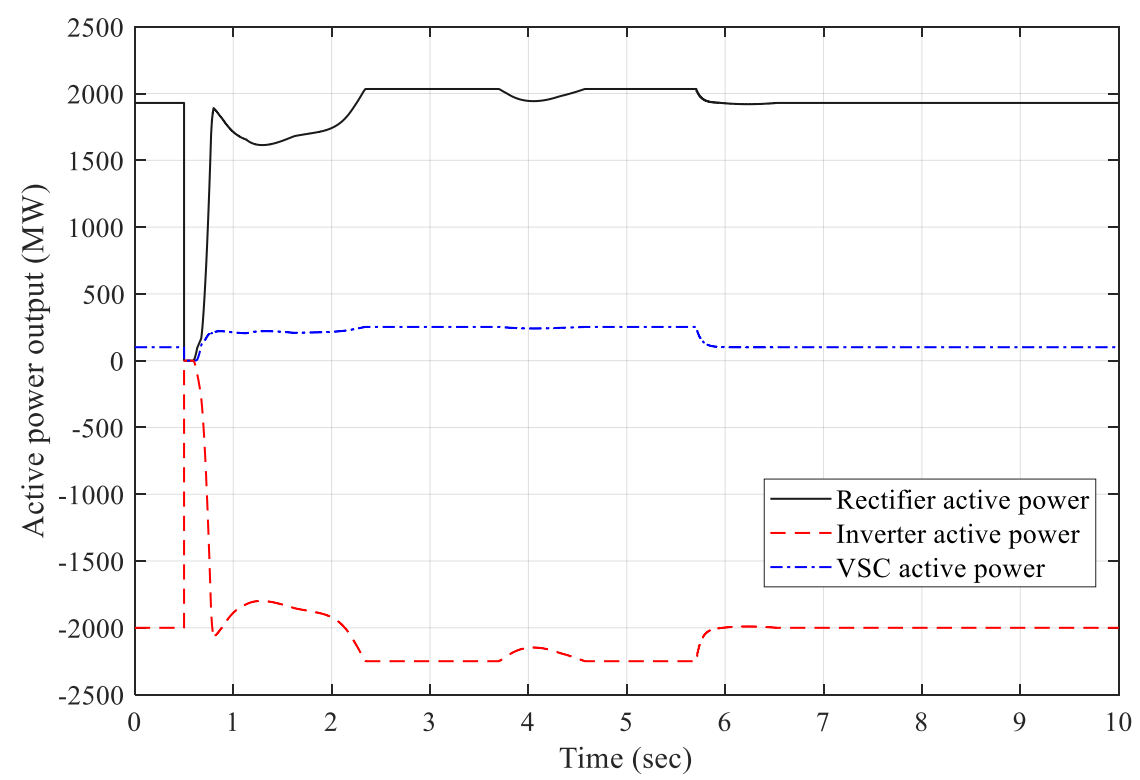

Figure 26. The active power outputs of the overload operation in the actual system data.

The severe load side event occurred and overload operation started after the event was cleared. The initial VSC output was $100 \mathrm{MW}$ and increased to $250 \mathrm{MW}$ during the overload operation. The overload operation was held for five seconds and the active power output of converters returned to the original value. For the event, the normal operation case was unstable after the event was cleared. Even though the voltage recovery feature was similar to the overload case until $1.5 \mathrm{~s}$, the system became unstable and the voltage swing occurred without overload operation. On the other hand, the system was stabilized by the overload operation.

\section{Conclusions}

A generic LCC MTDC model and a CRPS model were used in the approximate hybrid MTDC model; the MTDC model controlled the active power, and the reactive power was controlled by the CRPS model. The control of the hybrid MTDC model, in terms of the active power and the reactive power, was verified via simulations. The proposed modeling method is for a power system analysis, and the focus of the model is the independent control of the active power and the reactive power.

The operation strategy for the hybrid MTDC is proposed and evaluated, according to a dynamic simulation. The model was applied to the test system, and the operation strategy was evaluated. A multi terminal DC grid improved the AC system utilization, and the proposed operation strategy improved the transient stability of the power system. To add, the overload was considered and the effect was verified. The stability improvement by the operation strategy is verified in the actual system data as well. The hybrid MTDC system is applied in the Korean power system and the transient stability analysis was conducted. The hybrid DC system can reduce the generator outage in the severe contingency by the operation strategy proposed.

Author Contributions: The hybrid MTDC system modeling method and the operation strategy were proposed by S.H., S.S., M.Y., and G.J. The experiment results were collected and analyzed by S.H., S.S., M.Y., and G.J.

Funding: This research was supported by Korea Electric Power Corporation. (R18XA06-62) and under the framework of the international cooperation program managed by the National Research Foundation of Korea. (No. 2017K1A4A3013579).

Conflicts of Interest: The authors declare no conflict of interest. 


\section{References}

1. Gotham, D.J.; Heydt, G. Power flow control and power flow studies for systems with facts devices. IEEE Trans. Power Syst. 1998, 13, 60-65. [CrossRef]

2. Hingorani, N.G.; Gyugyi, L. Understanding FACTS: CONCEPTS and Technology of Flexible AC Transmission Systems; Wiley-IEEE Press: New York, NY, USA, 2000; p. 452.

3. Xiao, Y.; Song, Y.; Sun, Y. Power flow control approach to power systems with embedded facts devices. IEEE Trans. Power Syst. 2002, 17, 943-950. [CrossRef]

4. Gaigowal, S.R.; Renge, M. Some studies of distributed series facts controller to control active power flow through transmission line. In Proceedings of the 2013 International Conference on Power, Energy and Control (ICPEC), Sri Rangalatchum, Dindigul, India, 6-8 February 2013; pp. 124-128.

5. Jovcic, D.; Van Hertem, D.; Linden, K.; Taisne, J.-P.; Grieshaber, W. Feasibility of dc transmission networks. In Proceedings of the 2011 2nd IEEE PES International Conference and Exhibition on Innovative Smart Grid Technologies (ISGT Europe), Manchester, UK, 5-7 December 2011; pp. 1-8.

6. Rouzbehi, K.; Miranian, A.; Candela, J.I.; Luna, A.; Rodriguez, P. A generalized voltage droop strategy for control of multiterminal dc grids. IEEE Trans. Ind. Appl. 2015, 51,607-618. [CrossRef]

7. Xu, L.; Yao, L.; Bazargan, M. Dc grid management of a multi-terminal hvdc transmission system for large offshore wind farms. In Proceedings of the 2009 International Conference on Sustainable Power Generation and Supply, Nanjing, China, 6-7 April 2009; pp. 1-7.

8. Xu, L.; Yao, L. Dc voltage control and power dispatch of a multi-terminal hvdc system for integrating large offshore wind farms. IET Renew. Power Gener. 2011, 5, 223-233. [CrossRef]

9. Reeve, J. Multiterminal hvdc power systems. IEEE Trans. Power Appar. Syst. 1980, 2, 729-737. [CrossRef]

10. Nguyen, T.-T.; Son, H.-I.; Kim, H.-M. Estimating stability of mtdc systems with different control strategy. J. Electr. Eng. Technol. 2015, 10, 443-451. [CrossRef]

11. Beerten, J.; Cole, S.; Belmans, R. Generalized steady-state vsc mtdc model for sequential ac/dc power flow algorithms. IEEE Trans. Power Syst. 2012, 27, 821-829. [CrossRef]

12. Haileselassie, T.M.; Uhlen, K. Impact of dc line voltage drops on power flow of mtdc using droop control. IEEE Trans. Power Syst. 2012, 27, 1441-1449. [CrossRef]

13. Cao, J.; Du, W.; Wang, H.F.; Bu, S. Minimization of transmission loss in meshed ac/dc grids with vsc-mtdc networks. IEEE Trans. Power Syst. 2013, 28, 3047-3055. [CrossRef]

14. Haileselassie, T.M.; Uhlen, K. Primary frequency control of remote grids connected by multi-terminal hvdc. In Proceedings of the IEEE PES General Meeting, Providence, RI, USA, 25-29 July 2010; pp. 1-6.

15. Liu, Y.; Zhang, L.; Liang, H. Dc voltage adaptive droop control strategy for a hybrid multi-terminal hvdc system. Energies 2019, 12, 380. [CrossRef]

16. Haleem, N.M.; Rajapakse, A.D.; Gole, A.M.; Fernando, I.T. Investigation of fault ride-through capability of hybrid vsc-lcc multi-terminal hvdc transmission systems. IEEE Trans. Power Deliv. 2019, 34, 241-250. [CrossRef]

17. Nguyen, M.H.; Saha, T.K.; Eghbal, M. Master self-tuning vdcol function for hybrid multi-terminal hvdc connecting renewable resources to a large power system. IET Gener. Trans. Distrib. 2017, 11, 3341-3349. [CrossRef]

18. Guo, C.; Zheng, A.; Yin, Z.; Zhao, C. Small-signal stability of hybrid multi-terminal hvdc system. Int. J. Electr. Power Energy Syst. 2019, 109, 434-443. [CrossRef]

19. Bu, S.; Du, W.; Wang, H.; Liu, Y.; Liu, X. Investigation on economic and reliable operation of meshed mtdc/ac grid as impacted by offshore wind farms. IEEE Trans. Power Syst. 2017, 32, 3901-3911. [CrossRef]

20. Liang, J.; Jing, T.; Gomis-Bellmunt, O.; Ekanayake, J.; Jenkins, N. Operation and control of multiterminal hvdc transmission for offshore wind farms. IEEE Trans. Power Deliv. 2011, 26, 2596-2604. [CrossRef]

21. Silva, B.; Moreira, C.; Leite, H.; Lopes, J.P. Control strategies for ac fault ride through in multiterminal hvdc grids. IEEE Trans. Power Deliv. 2014, 29, 395-405. [CrossRef]

22. Reed, G.; Pape, R.; Takeda, M. Advantages of voltage sourced converter (vsc) based design concepts for facts and hvdc-link applications. In Proceedings of the 2003 IEEE Power Engineering Society General Meeting, Toronto, ON, Canada, 13-17 July 2003.

23. Zhao, Z.; Iravani, M. Application of GTO voltage source inverter in a hybrid hvdc link. IEEE Trans. Power Deliv. 1994, 9, 369-377. [CrossRef] 
24. Yuan, X.; Cheng, S. Performance analysis of a hybrid multi-terminal hvdc system. In Proceedings of the 2005 International Conference on Electrical Machines and Systems, Nanjing, China, 27-29 September 2005; pp. 2169-2174.

25. Yuan, X.; Cheng, S.J. Simulation study for a hybrid multi-terminal hvdc system. In Proceedings of the 2005/2006 IEEE/PES Transmission and Distribution Conference and Exhibition, Dallas, TX, USA, 21-24 May 2006; pp. 720-725.

26. Chen, X.; Sun, H.; Wen, J.; Lee, W.-J.; Yuan, X.; Li, N.; Yao, L. Integrating wind farm to the grid using hybrid multiterminal hvdc technology. IEEE Trans. Ind. Appl. 2011, 47, 965-972. [CrossRef]

27. Li, C.; Zhan, P.; Wen, J.; Yao, M.; Li, N.; Lee, W.-J. Offshore wind farm integration and frequency support control utilizing hybrid multiterminal hvdc transmission. IEEE Trans. Ind. Appl. 2014, 50, 2788-2797. [CrossRef]

28. Torres-Olguin, R.E.; Molinas, M.; Undeland, T. Offshore wind farm grid integration by vsc technology with lcc-based hvdc transmission. IEEE Trans. Sustain. Energy 2012, 3, 899-907. [CrossRef]

29. Krishnayya, P.; Lefebvre, S.; Sood, V.; Balu, N. Simulator study of multiterminal hvdc system with small parallel tap and weak ac systems. IEEE Trans. Power Appar. Syst. 1984, 103, 3125-3132. [CrossRef]

30. Athay, T.; Podmore, R.; Virmani, S. A practical method for the direct analysis of transient stability. IEEE Trans. Power Appar. Syst. 1979, 98, 573-584. [CrossRef]

31. Yoon, M.; Yoon, Y.-T.; Jang, G. A study on maximum wind power penetration limit in island power system considering high-voltage direct current interconnections. Energies 2015, 8, 14244-14259. [CrossRef]

32. Ferreira, C.M.; Barbosa, F.M.; Agreira, C.F. Transient stability preventive control of an electric power system using a hybrid method. In Proceedings of the 2008. 12th International Middle-East Power System Conference (MEPCON), Aswan, Egypt, 12-15 March 2008; pp. 141-145.

33. Siemens Power Technologies International. PSS/E 33.4 Model Library, 1st ed.; Siemens Power Technologies International: Schenectady, NY, USA, 2013.

34. Pinto, R.T.; Rodrigues, S.; Bauer, P.; Pierik, J. Grid code compliance of vsc-hvdc in offshore multi-terminal dc networks. In Proceedings of the IECON 2013-39th Annual Conference of the IEEE Industrial Electronics Society, Vienna, Austria, 10-13 November 2013; pp. 2057-2062.

35. Amin, M.; Molinas, M.; Lyu, J.; Cai, X. Impact of power flow direction on the stability of vsc-hvdc seen from the impedances nyquist plot. IEEE Trans. Power Electron. 2016, 32, 8204-8217. [CrossRef]

(C) 2019 by the authors. Licensee MDPI, Basel, Switzerland. This article is an open access article distributed under the terms and conditions of the Creative Commons Attribution (CC BY) license (http://creativecommons.org/licenses/by/4.0/). 